\title{
1 Redox regulation of PTPN22 affects the severity of T cell dependent
}

6 Holmdahl ${ }^{1,13^{*}}$

\section{Affiliations: \\ Affiliations:}

\section{autoimmune inflammation}

Jaime James ${ }^{1}$, Yifei Chen ${ }^{2,3}$, Clara M. Hernandez ${ }^{1,4}$, Florian Forster ${ }^{1,5}$, Markus Dagnell ${ }^{2}$, Qing Cheng ${ }^{2}$, Amir A. Saei ${ }^{6,7}$, Hassan Gharibi ${ }^{6}$, Gonzalo Fernandez Lahore ${ }^{1}$, Annika Åstrand ${ }^{8}$, Rajneesh Malhotra ${ }^{9}$, Bernard Malissen ${ }^{10}$, Roman A. Zubarev ${ }^{6,11}$, Elias S.J. Arnér ${ }^{2,12}$, Rikard

${ }^{1}$ Division of Medical Inflammation Research, Dept. of Medical Biochemistry and Biophysics, Karolinska Institute, Stockholm, Sweden.

2Division of Biochemistry, Dept. of Medical Biochemistry and Biophysics, Karolinska Institute, Stockholm, Sweden.

${ }^{3}$ Department of Gastroenterology, the First Affiliated Hospital of Xi'an Jiaotong University, Xi'an, Shaanxi, 710061, P.R. China.

${ }^{4}$ Current address: Monash University, School of Public Health and Preventive Medicine, Melbourne, Australia.

${ }^{5}$ Current address: SCIOTEC Diagnostic Technologies GmbH, Tulln, Austria.

${ }^{6}$ Division of Physiological Chemistry I, Dept. of Medical Biochemistry and Biophysics,

Karolinska Institute, Stockholm, Sweden.

${ }^{7}$ Department of Cell Biology, Harvard Medical School, Boston, MA, USA.

${ }^{8}$ Project Leader Department, Research and Early Development, Respiratory \& Immunology, BioPharmaceuticals R\&D, AstraZeneca, Gothenburg, Sweden. 
${ }^{9}$ Translational Science and Experimental Medicine, Research and Early Development, Respiratory \& Immunology, BioPharmaceuticals R\&D, AstraZeneca, Gothenburg, Sweden.

${ }^{10}$ Centre d'Immunophénomique, Aix Marseille Université, INSERM, CNRS UMR, 13288

Marseille, France.

${ }^{11}$ Department of Pharmacological \& Technological Chemistry, I.M. Sechenov First Moscow State Medical University, Moscow, 119146, Russia.

${ }^{12}$ Department of Selenoprotein Research, National Institute of Oncology, Budapest, Hungary.

${ }^{13}$ The Second Affiliated Hospital of Xi'an Jiaotong University (Xibei Hospital), 710004, Xi'an, China.

${ }^{*}$ Corresponding author, Rikard Holmdahl, ${ }^{1}$ Division of Medical Inflammation Research, Dept. of Medical Biochemistry and Biophysics, Karolinska Institute, Stockholm, Sweden.

Email: rikard.holmdahl@ki.se

Classification: Biological Sciences/ Immunology and Inflammation

Keywords: PTPN22, autoimmunity, redox regulation

\section{Abstract}

Chronic autoimmune diseases are associated with mutations in PTPN22, a modifier of T cell receptor signaling. As with all protein tyrosine phosphatases the activity of PTPN22 is redox regulated, but if or how such regulation can modulate inflammatory pathways in vivo is not known. To determine this, we created a mouse with a cysteine-to-serine mutation at position 129 in PTPN22 (C129S), a residue proposed to alter the redox regulatory properties of PTPN22 by forming a disulfide with the catalytic C227 residue. The C129S mutant mouse showed a stronger $\mathrm{T}$ cell-dependent inflammatory response and development of $\mathrm{T}$ cell dependent autoimmune arthritis due to enhanced TCR signaling and activation of T cells, an effect neutralized by a mutation in Ncf1, a component of the NOX2 complex. Activity assays with 
purified proteins suggest that the functional results can be explained by an increased sensitivity to oxidation of the C129S mutated PTPN22 protein. We also observed that the disulfide of native PTPN22 can be directly reduced by the thioredoxin system, while the C129S mutant lacking this disulfide was less amenable to reductive reactivation. In conclusion, we show that PTPN22 functionally interacts with Ncf1 and is regulated by oxidation via the noncatalytic C129 residue and oxidation-prone PTPN22 leads to increased severity in the development of T cell-dependent autoimmunity.

Significance statement: A hitherto unstudied aspect of PTPN22 biology is its regulation by cell redox states. Here we created a mouse model where PTPN22 was mutated to respond differentially to redox levels in vivo and found that PTPN22 function is regulated by reactive oxygen species and that redox regulation of PTPN22 impacts T-cell-dependent autoimmune inflammation. 


\section{Introduction}

Complex autoimmune diseases affect $4-5 \%$ of the human population and large efforts have been invested in finding the underlying genetic polymorphisms [1]. Though a major genetic contribution comes from the major histocompatibility complex region, many other loci have also been identified. Two important single nucleotide polymorphisms (SNPs) have emerged, one located in PTPN22 [2], a cytoplasmic class I protein tyrosine phosphatase (PTP), and the other in NCF1 [3][4], a component of the NOX2 complex, controlling induction of reactive oxygen species (ROS) in antigen presenting cells. Mutations in Ncf1, leading to a lower NOX2 dependent ROS response, have been shown to be a major predisposing genetic factor for autoimmune diseases in both mice and humans [3][4]. PTPN22 is primarily a dominant negative regulator of $\mathrm{T}$ cell responsiveness, acting by dephosphorylating important target proteins in the T cell signaling machinery including LCK, FYN and ZAP70 [5][6]. Studies on PTPN22 have thus far focused on the effects of knocking out the gene or on the autoimmune variant PTPN22-R620W, but with divergent results [7]. Importantly, however, PTPN22 is likely to be redox regulated. Its activity is, as with other protein tyrosine phosphatases (PTPs), dependent upon the integrity of a catalytic active site Cys residue. The reactivity of this cysteine makes it particularly susceptible to oxidation via reactive oxygen species (ROS) leading to concomitant abrogation of PTP activity. Reversible oxidation and reduction of such reactive cysteines has previously been shown to be a regulatory mechanism in signal transduction, regulating important $\mathrm{T}$ cell downstream signaling molecules such as NF-KB, NRF2, MAPK and ERK [8]-[9]. Control of redox regulation of PTPs in cells depends upon the balance between inhibitory oxidation of the catalytic Cys residue and its activation by reduction, where the latter is typically maintained by the thioredoxin system. We have now investigated the possibility that redox regulation of PTPN22 could modulate inflammatory 
pathways in vivo. Interestingly, the PTPN22 catalytic cysteine (C227) has been suggested to form a disulfide bond with another "back-door" cysteine (C129), possibly altering the threshold for irreversible oxidation of $\mathrm{C} 227$ and thereby affecting the redox state of the active site [10]. By creating a mouse with a cysteine-to-serine mutation at position 129 in PTPN22 (C129S) we could investigate the possible pathophysiological impact of its redox regulatory properties in vivo. We found that mice with this amino acid replacement developed increased T cell-dependent inflammatory responses due to enhanced T cell receptor signaling, which was dependent on NOX2-produced ROS. This correlated well with findings of a lower overall turnover, higher sensitivity to inhibitory oxidation, and a lower capacity of reductive reactivation by the thioredoxin system of recombinant mutant PTPN22 ${ }^{\mathrm{C} 129 \mathrm{~S}}$, as compared to wild-type PTPN22. These results show that redox regulation of PTPN22 modulates inflammation in vivo, with a lower resistance to oxidation of PTPN22 promoting aggravated disease.

\section{Results}

Recombinant PTPN22 ${ }^{\mathrm{C} 1295}$ has lower catalytic activity, higher sensitivity to inhibition by oxidation and lower capacity for reductive reactivation by the thioredoxin system

To investigate the potential impact of a C129S replacement in the PTPN22 protein, we recombinantly produced the catalytic domain of the corresponding human wild-type PTPN22 and PTPN22 ${ }^{\mathrm{C} 129 \mathrm{~S}}$ mutant proteins (the $\mathrm{C} 129$ and the catalytic $\mathrm{C} 227$ residues have the same numbering in both mouse and human). The recombinant proteins were purified to $>95 \%$ purity as judged by SDS-PAGE and kinetic parameters were determined using p-NPP as substrate; wild-type PTPN22 enzyme had a basal turnover of $19.6 \mathrm{~min}^{-1}$ with a $\mathrm{K}_{\mathrm{m}}$ of $4.57 \mathrm{mM}$ while PTPN22 ${ }^{\mathrm{C} 129 \mathrm{~S}}$ displayed a turnover of $11.9 \mathrm{~min}^{-1}$ and a $\mathrm{K}_{\mathrm{m}}$ of $8.02 \mathrm{mM}$ under the same 
conditions, showing that the C129S protein has retained PTP activity but with an overall lower catalytic efficiency (Fig. 1A) which confirms Tsai et al.'s results [10].

Next, we wanted to assess sensitivity of pre-reduced wild-type PTPN22 to inhibition by oxidation. We found that addition of $50 \mu \mathrm{M} \mathrm{H}_{2} \mathrm{O}_{2}$ to the pure protein led to inhibition of approximately half the activity after 20 min incubation (Fig. 1B). We also found that addition of bicarbonate together with $\mathrm{H}_{2} \mathrm{O}_{2}$ noticeably potentiated the inactivation (Fig. $1 \mathrm{C}$ ), similar to the properties shown earlier for PTP1B that are likely due to formation of peroxymonocarbonate that reacts more efficiently than $\mathrm{H}_{2} \mathrm{O}_{2}$ with the PTP enzyme [11]. When comparing the $\mathrm{H}_{2} \mathrm{O}_{2}$-sensitivity of PTPN22 ${ }^{\mathrm{C} 129 \mathrm{~S}}$ with that of wild-type PTPN22, we found that the mutant enzyme was clearly more sensitive to inhibition by $\mathrm{H}_{2} \mathrm{O}_{2}$ than wild-type PTPN22, although it had a lower basal turnover (Fig. 1D). The same effect was also seen in the presence of a functional thioredoxin system of thioredoxin reductase 1 (TrxR1) coupled with thioredoxin (Trx1), but perhaps less so coupled with thioredoxin related protein of 14 kDa (TRP14) (Fig. 1E). It should be noted that also PTP1B displays different reactivities with Trx1 and TRP14 [12], which may have physiological importance.

True redox regulation of PTPN22 requires that the fully oxidized and thus inactivated enzyme can be subsequently reactivated by reduction. Since the thioredoxin system has been previously shown to reactivate phosphatases PTP1B and PTEN [11][13][16], we next tested this property. We found that $\mathrm{H}_{2} \mathrm{O}_{2}$-inactivated PTPN22 species could be re-activated in vitro using either DTT as reductant, or the thioredoxin system composed of NADPH together with TrxR1 and Trx1. Interestingly, wild-type PTPN22, but not the PTPN22 ${ }^{\mathrm{C} 129 \mathrm{~S}}$ mutant, could be 128 directly reactivated by TrxR1 together with NADPH, without inclusion of Trx1 (Fig. 2A). 
concentration dependent and that the oxidized forms of wild-type PTPN22 were clearly more amenable to direct reactivation by TrxR1 than those of PTPN22 ${ }^{\mathrm{C} 129 \mathrm{~S}}$ (Fig. 2B). Since the only difference between PTPN22 and PTPN22 ${ }^{\mathrm{C} 1295}$ is the integrity of the non-catalytic $\mathrm{C} 129$ residue, we reasoned that the direct reductive reactivation by TrxR1+NADPH of wild-type PTPN22, not seen with the PTPN22 ${ }^{\mathrm{C} 129 \mathrm{~S}}$ mutant, might indicate that TrxR1 can directly reduce the disulfide involving C129 that may be formed in the wild-type PTPN22 enzyme. To assess this possibility, we subjected both forms of the enzyme to oxidative conditions, or to reduction by either DTT or TrxR1, and then analyzed the enzymes on a non-reducing SDS-PAGE. Indeed, only PTPN22 but not PTPN22 ${ }^{\mathrm{C} 129 \mathrm{~S}}$ displayed a second faster migrating form of the protein upon oxidation that disappeared upon reduction with DTT or TrxR1 (Fig. 2C). The effect was seen with several concentrations of $\mathrm{H}_{2} \mathrm{O}_{2}$ and DTT treatment could always revert the double band of PTPN22 (Suppl. Fig. S1). We also found that the reactivation of wild-type PTPN22, with either DTT or the thioredoxin system (TrxR1 alone, or coupled with either Trx1 or TRP14), was always more efficient than that of the mutant PTPN22 $2^{\mathrm{C} 126 \mathrm{~S}}$ enzyme, also in cases where prior oxidation was further potentiated by bicarbonate (Suppl. Fig. S2).

These findings with recombinant human PTPN22 and PTPN22 ${ }^{\mathrm{C} 1295}$ enzymes suggest that the mutant is more amenable to oxidation and that the thioredoxin system is less efficient in reactivating its oxidized form. The notion that TrxR1 directly can reduce the disulfide which is not formed in the mutant enzyme, but which may be formed upon oxidation of wild-type PTPN22, was interesting, as to our knowledge no PTP has earlier been shown to form a disulfide species that is a direct substrate of TrxR1. Based upon these findings, we propose a

151 model for redox regulation of PTPN22 (Fig. 2D), which illustrates how PTPN22 ${ }^{\mathrm{C} 129 \mathrm{~S}}$ can be more easily inactivated than the wild-type enzyme. Next, we wished to assess if mutant PTPN22 ${ }^{\mathrm{C} 129 \mathrm{~S}}$ yields any phenotypic effects in mouse models of inflammation. 


\section{Establishment of PTPN22 ${ }^{\mathrm{C} 129 \mathrm{~S}}$ mutant mice}

To study redox-dependent regulation of PTPN22 in vivo and its possible downstream effects on inflammation we generated a mouse with the PTPN22 ${ }^{\mathrm{C} 1295}$ mutation (schematic in Fig. 3A). This disrupts the mechanism by which the catalytic $\mathrm{C} 227$ can be protected through formation of a disulfide that can be reduced by TrxR1 (Fig. 2D), thus making PTPN22 ${ }^{\mathrm{C} 1295}$ in the mice more prone to inactivation by oxidation. The mice were backcrossed to C57BI6/N mice together with a major histocompatibility complex $(M H C)$ region containing an $A q M H C$ class I/ allele, making it susceptible to autoimmune arthritis [15], and also with the $m 1 j$ mutation of Ncf1 [16], allowing interaction studies.

\section{PTPN22 $^{\mathrm{C129S}}$ enhances Th1-mediated inflammation via NOX2-mediated ROS}

To study the effect of PTPN22 $2^{\mathrm{C} 129 \mathrm{~S}}$ on cell-mediated immunity we used the delayed-type hypersensitivity (DTH) model, which is known to drive inflammation via IFNy producing type $1 \mathrm{~T}$ helper cells (Th1) [17]. Littermate wild-type and PTPN22 ${ }^{\mathrm{C} 129 \mathrm{~S}}$ mice were immunized with heterologous collagen type II (COL2), challenged on day 8 by injection with the same antigen in the ear and subsequently, swelling was assessed. We observed increased ear pinna thickness in PTPN22 ${ }^{\mathrm{C} 129 \mathrm{~S}}$ mice 24, 48 and 72 hours after challenge compared to littermate wildtype mice (Fig. 3B). In contrast, PTPN22 ${ }^{\mathrm{C} 129 \mathrm{~S}}$ did not enhance ear swelling in NCF1 mutant mice with a lack of NOX2 activity (Fig. 3C)[18]. To assess the antigen-specific T cell response we restimulated cells from inguinal lymph nodes with the immunodominant COL2 peptide (259273) and observed a marked increase in IFNy and IL-2 producing PTPN22 ${ }^{\mathrm{C} 1295}$ cells when comparing wild-type supporting a Th1 phenotype (Fig. 3D, 3E). No difference was observed on the NCF1 mutant background. Within the ears, flow cytometry analysis showed that the challenge with COL2 increased percentages of CD45+ leucocytes and CD45+TCRb+ cells as 
compared to PBS injection with the NCF1 mutants showing higher cell infiltration even in PBS-

injected ears (Fig. 3F). Additionally, we observed higher CD4 expression in COL2-injected PTPN22 ears as compared to wild-type with no difference in the NCF1 mutants (Fig.3G). To further support the Th1 phenotype we performed qPCR analysis of the ears which showed increased expression of CXCR3 in inflamed PTPN22 $2^{\mathrm{C} 129 \mathrm{~S}}$ ears (Fig. $3 \mathrm{H}$ ).

In the periphery, immunized PTPN22 ${ }^{\mathrm{C} 129 \mathrm{~S}}$ mice had increased cell numbers in the spleen as compared to wild-type (Fig. 3I). Within the inguinal lymph nodes we observed a reduction in CD4+ $T$ cells which expressed higher levels of CD44, a marker for effector-memory $T$ cells (Fig.3J). This was not seen in circulating $T$ cells within the blood, however there was a significant reduction in FOXP3+ T cells in PTPN22 ${ }^{\mathrm{C} 129 \mathrm{~S}}$ mice 48 hours after initial immunization (Fig. S3A).

As we observed differences in T cell activation levels, we wanted to address the role of PTPN22 ${ }^{\mathrm{C} 1295}$ in antigen-specific T cells. To do this, we used the V $\beta 12$-transgenic mouse (V $\beta 12-$ $\operatorname{tg})$ which expresses a TCR $\beta$ chain specific for the galactosylated COL2 (260-270) epitope and can be tracked using the clonotypic B22a1 antibody. Upon priming of V $\beta 12$-tg mice with COL2 these T cells expand 50-fold, acquire an activated phenotype and play an important role in the early phase of the arthritogenic immune response [19]. Upon immunization with COL2, PTPN22 ${ }^{\mathrm{C} 129 \mathrm{~S}}$ did not affect the expansion of antigen-specific V $312+$ T cells per se (Fig. 3K), but did change their activation status: COL2 reactive $\mathrm{T}$ cells in the periphery expressed higher levels of CD44 on CD4+ T cells as compared to wild-type (Fig. 3K). In the DTH model, we could also observe higher B22a1 expression among CD4+ T cells in the inflamed ears of Vß12.PTPN22 ${ }^{\mathrm{C} 129 \mathrm{~S}}$ mice (Fig. 3L). 
Together, these results indicate that the oxidation prone PTPN22 ${ }^{\mathrm{C} 129 \mathrm{~S}}$ mutant enhances T cellmediated inflammation. Conversely, wild-type PTPN22 with a higher basal activity and more resistance to oxidation counteracts these inflammatory processes.

\section{PTPN22 ${ }^{\mathrm{C} 129 \mathrm{~S}}$ enhances T cell responses and development of arthritis}

As PTPN22 is heavily associated with the development of autoimmunity we also sought to explore the effects of PTPN22 ${ }^{\mathrm{C} 129 \mathrm{~S}}$ on arthritis development by using the glucose-6-phosphateisomerase peptide (GPIp)-induced arthritis model (GIA), which causes acute autoimmunity that resembles the early stages of rheumatoid arthritis, and which is regulated by NOX2derived $\operatorname{ROS}[20,21][21]$. As shown in Fig. 4A, we observed increased arthritis severity in PTPN22 ${ }^{\mathrm{C} 129 \mathrm{~S}}$ mice from day 10 up to day 22 after onset as well as increased incidence in mutant mice. On the NCF1 deficient background we observed a trend in the opposite direction with PTPN22 ${ }^{\mathrm{C} 129 \mathrm{~S}}$ mice showing less disease and no significant difference in disease incidence (Fig. 4B).

Increased disease was further supported by higher antigen-specific $T$ cell responses in PTPN22 ${ }^{\mathrm{C} 129 \mathrm{~S}}$ mice as shown by increased numbers of IFNy-secreting T cells, both upon GPIp and anti-CD3/anti-CD28 stimulation (Fig. 4C). CD4 T cells in the draining lymph nodes exhibited increased activation as evidenced by higher numbers of CD4+CD69+, CD4+CD25+FOXP3+ and CD4+PD1+ T cells (Fig. 4D). No differences were observed in serum antibody levels against the hGPI peptide (Fig. 4E). In summary, PTPN22 $2^{\mathrm{C} 129 \mathrm{~S}}$ enhances autoimmune inflammation due to enhanced T cell reactivity. 
To understand where the observed T cell activation phenotype in PTPN22 ${ }^{\mathrm{C} 129 \mathrm{~S}}$ mice originates from, we first confirmed that PTPN22 expression was comparable between wild-type, PTPN22 ${ }^{\mathrm{C} 129 \mathrm{~S}}$, NCF1 ${ }^{\mathrm{m} 1 \mathrm{~s}}$ and PTPN22 ${ }^{\mathrm{C} 129 \mathrm{~S}} / \mathrm{NCF} 1^{\mathrm{m} 1 \mathrm{~J}}$ mice, both via mRNA and protein analysis (Fig. 5A-B; Fig. S3B). Next, we analyzed expansion of naïve immune cell populations. PTPN22 ${ }^{\mathrm{C} 129 \mathrm{~S}}$ was found to not affect immune cell populations in peripheral lymphoid organs in naïve mice; the percentages of $\mathrm{B}$ cells $\left(\mathrm{B} 220^{+}\right)$, $\mathrm{T}$ cells $\left(\mathrm{CD}^{+}\right)$, dendritic cells $\left(\mathrm{CD} 11 \mathrm{c}^{+}\right)$and macrophages $\left(\mathrm{CD} 11 \mathrm{~B}^{+}\right)$were comparable to wild-type littermates as was $\mathrm{MHC}$ II expression on antigenpresenting cells (Fig. S3C).

As PTPN22 has been previously shown to affect T cell tolerance [14][15], we analyzed T cell development in the thymus. We observed a slight reduction in the percentage of CD4-CD8(DN) population whilst $\mathrm{CD} 4^{+} \mathrm{CD} 8^{+}(\mathrm{DP}), \mathrm{CD}^{+}$, and $\mathrm{CD} 8^{+}$were comparable between groups. Further fractionation of the early $\mathrm{CD}^{-} \mathrm{CD} 8^{-}$progenitor population showed a slight increase in DN1 (CD44 $\left.{ }^{+} \mathrm{CD} 25^{\circ}\right)$ and decrease in DN4 (CD44-CD25) populations in $\mathrm{PTPN}^{-} 2^{\mathrm{C} 1295}$ thymi (Fig. 5C). No changes were observed in TCRb, CD5 and CD69 expression (Fig. 5C). Percentages of $\mathrm{CD}^{+}$and $\mathrm{CD} 8^{+} \mathrm{T}$ cells as well as expression of CD44, and CD69 activation markers on CD4+ $\mathrm{T}$ cells were not affected (Fig.5D). Furthermore, percentages of CD4+FOXP3+ and $\mathrm{CD} 4+\mathrm{FOXP} 3+\mathrm{CD} 25+$ cells were comparable between groups in thymus and peripheral lymphoid organs. (Fig. 5D).

As we consistently observed a differential T cell phenotype in mice with mutated PTPN22 ${ }^{\mathrm{C} 129 \mathrm{~S}}$

241 in vivo, we studied T cell function in vitro. To assess signaling, we measured $\mathrm{Ca}^{2+}$-flux, one of 242 the earliest signaling events upon TCR engagement and observed slighly increased 243 intracellular $\mathrm{Ca}^{2+}$ in PTPN22 ${ }^{\mathrm{C} 1295}$ CD4 T cells upon anti-CD3 stimulation (Fig. 5E). Proliferation 
of CD4 T cells, as assessed by CellTrace dilution, was also increased upon anti-CD3/antiCD28

stimulation (Fig. 5F). We observed increased activation of ex vivo-stimulated CD4 T cells as

measured by the early T cell activation marker CD69 as well as markedly different IFNy

production resembling the in vivo results (Fig.5G-H).

\section{Enhanced phosphorylation of PTPN22 targets and enhanced PKC expression in PTPN22 ${ }^{\mathrm{C} 1295}$}

cells

To assess whether the differences in T cell reactivity could be correlated with altered PTPN22

Y420 and Y394 of the Src family kinases Fyn and LCK, respectively as well as of Y493 of Zap70,

thus agreeing well with lower intracellular phosphatase activity of the PTPN22 ${ }^{\mathrm{C} 129 \mathrm{~S}}$ mutant protein (Fig. 6A-B) and confirming findings with recombinant PTPN22 proteins.

Next, we wanted to assess if downstream $\mathrm{T}$ cell-signaling mediators were affected by

PTPN22 ${ }^{\mathrm{C} 129 \mathrm{~S}}$. TCR-signaling induces activation of protein kinase $\mathrm{C}(\mathrm{PKC})-\theta$, an essential player in peripheral T cell activation. As compared to wild-type, PTPN22 $2^{\mathrm{C} 129 \mathrm{~S}}$ /ymph node cells showed constitutive phosphorylation of Y538 on PKC- $\theta$, independent of TCR stimulation whereas in wild-type cells phosphorylation increased with TCR stimulation, hinting at higher basal activity of PKC- $\theta$ in the mutant (Fig. 6C). To assess how changes in the redox status affect $\mathrm{T}$ cell signaling we used buthionine sulphoximine (BSO), an inhibitor of $y$-glutamyl-cysteine synthetase, which is essential for glutathione synthesis. Treatment with BSO increases the oxidative burden in cells without directly affecting the thioredoxin system. Here, it initially reverted the phospho-PKC- $\theta$ levels in the mutant to be comparable with wild-type, followed by a slower TCR-activation-dependent phosphorylation (Fig. 6C). Next, we investigated how 
differential signaling was affecting the proteome signature using sorted CD4+ $T$ cells from wild-type and PTPN22 ${ }^{\mathrm{C} 129 \mathrm{~S}}$ mice. Mass spectrometric proteomics analysis of activated cells revealed differential expression of multiple genes under both untreated and BSO-treated conditions: Up-regulation of Nudt16/1 [18, 19] , Clic4 [26], Mgmt [27], Hsp [28], Serpina1e [29] and Fscn1 [30] as well as down-regulation of Fuca1 [31] and Rps6kb1 [32] have all been shown to be associated with increased PKC signaling (Fig. 6D).

Thus, PTPN22 ${ }^{\mathrm{C} 129 \mathrm{~S}}$ that is prone to inactivation by oxidation with decreased catalytic activity results in enhanced T cell signaling, which has broad signaling effects that can yield aggravated

275 inflammatory disease.

\section{Discussion}

In this study we investigated whether redox regulation of PTPN22 has an impact on inflammation and autoimmune arthritis. We found that the C129S mutation in Ptpn22 leads to reduced catalytic activity and increased susceptibility to oxidative inactivation in vitro, causing concomitant upregulation of T-cell activation and T-cell-mediated autoimmunity in a NOX2-dependent manner.

Redox regulation describes the modulation of signaling pathways by oxidation and reduction, the effects of which must always be considered in relation to enzymatically driven oxidative and reductive pathways, and the signaling properties of redox-modified cellular targets [33][34]. Significant ROS producers include the membrane-bound NADPH oxidase (NOX) complexes as well as the mitochondrial respiratory chain, modulating responses such as cell growth, death and immune function under both physiological and pathological conditions [35]38]. The interplay between redox signaling and the immune response is complex and 
multi-faceted. The protective effects of ROS against inflammatory diseases in vivo is best evidenced in the $N c f 1^{m 1 J}$ mouse where diminished ROS leads to exacerbated inflammation in arthritis and lupus models [18][37]. In T cells, ROS, most likely derived from NOX2 expressing antigen presenting cells have been shown to regulate NFAT activation, IL2 production and plasticity by both influencing the redox status of kinases involved as well as through metabolic reprogramming [8][38][39]. The list of intracellular signaling molecules regulated by ROS is long: transcription factors such as Nrf2/Keap1, NF-kB, HIF-1a, AP-1 as well as key TCR downstream mediators such as MAPK/ERK, LCK, Zap70, LAT, PKC- $\theta$ and PLC 1 are all redoxsensitive [40]. The impact of the thioredoxin- and glutathione-dependent reductive systems on these signaling pathways is also of crucial importance [34][41].

Reversible cysteine modifications have emerged as a major redox regulatory mechanism important for ERK1/2 phosphorylation, calcium flux, cell growth, and proliferation of naïve CD4+ and CD8+ T cells [42]. Proteins containing cysteine residues, such as protein tyrosine phosphatases (PTPs), are particularly susceptible to redox effects in part due to the low pKa value of their active site. Oxidation leads to inhibition of PTP activity and several PTPs such as Src homology region 2 domain-containing phosphatase-1 and 2 (SHP1/2) and tyrosine-protein phosphatase non-receptor type 1 (PTP1B) are well studied in terms of their redox regulation [9][43][44][45]. Again, the balance between oxidative and reductive pathways is crucial for overall PTP activities and in this context the thioredoxin system is important for its reductive PTP-activating capacity [13][46][47].

PTPN22 is a protein tyrosine phosphatase expressed in all hematopoietic cells and a known negative regulator of T cell signaling. The R620W variant of PTPN22 has been associated with an increased risk of several autoimmune diseases, amongst them diabetes, rheumatoid 
arthritis and systemic lupus erythematosus. It has been shown to interfere with the binding

of PTPN22 to the C-terminal SRC kinase (CSK) affecting downstream signaling. However, whether R620W is a gain-of-function or loss-of-function variant remains controversial [24][25][48]. A possibility for redox regulation of PTPN22 was highlighted by Tsai et al. who discovered an atypical disulfide bond formation between the catalytic cysteine C227 and a "back-door" cysteine C129, as visualized in a crystal structure of the catalytic domain of PTPN22 [10]. As physiologically relevant oxidative regulation of PTPN22 has thus far not been studied, we decided to mutate C129 into a serine, thereby abrogating the capacity of C129 to contribute to redox regulation of PTPN22, both in vitro and in vivo.

In our in vitro experiments, PTPN22 ${ }^{\mathrm{C} 129 \mathrm{~S}}$ showed a lower basal catalytic activity, higher sensitivity to inhibition by oxidation, and a lower capacity for reactivation by the thioredoxin system, compared to the wildtype enzyme. The reason behind the initial drop in activity remains to be studied; the single cysteine-to-serine change may affect the PTPN22 protein conformation or dynamics and crystallography studies would be needed to address this. It should also be noted that the pure PTPN22 ${ }^{\mathrm{C} 129 \mathrm{~S}}$ migrated slightly slower than wild-type PTPN22, despite the only difference between the two proteins being the single C129 residue. This also suggests an overall effect on protein characteristics by the C129S mutation, which should be studied further. Based on our findings, we propose a model for the redox regulation of PTPN22, with the disulfide bond that can be formed between C227 and C129 protecting the catalytic $\mathrm{C} 227$ residue from overoxidation to sulphinic or sulphonic acid. It is also possible that an alternative sulphenylamide motif can be made between the thiol group of the C227 with the peptide bond amine, which can also be reduced by the thioredoxin system, similar to that seen with PTP1B [13][14] even if that motif was not seen in the crystal structure of PTPN22 [10]. This model explains how PTPN22 ${ }^{\mathrm{C} 129 \mathrm{~S}}$ can still show activity and a certain protection 
against oxidation and reactivation by the thioredoxin system, but simultaneously be more susceptible to oxidation because the protective disulfide cannot be formed.

In T cells, the PTPN22 ${ }^{\mathrm{C} 129 \mathrm{~S}}$ mutation led to enhanced T cell activation and proliferation. This

was not due to altered PTPN22 expression levels, but rather a consequence of downstream

signaling. The PTPN22 targets LCK, Fyn and Zap70 showed increased phosphorylation, arguing for lower catalytic activity of PTPN22 $2^{\mathrm{C} 129 \mathrm{~S}}$ in vivo and confirming our in vitro findings. In TCR signaling, phosphorylation of PKC- $\theta$ is a late-stage event that leads to the activation of transcription factors Nf-Kb, NFAT and AP-1 controlling T cell functions down the line [49]. We observed baseline upregulation of $\mathrm{p}-\mathrm{PKC}-\theta$ in PTPN22 ${ }^{\mathrm{C} 129 \mathrm{~S}}$ T cells which did not respond to further TCR stimulation. PKC phosphorylation is regulated by GLK (germinal center kinase- like kinase) and LCK [49]-[51]. An increase in LCK phosphorylation as previously observed might therefore be causing increased p-PKC- $\theta$. In an oxidative microenvironment created by BSO treatment, the initial difference in unstimulated cells disappeared and PTPN22 ${ }^{\mathrm{C} 129 \mathrm{~S}}$ instead showed slower phosphorylation kinetics compared to wild-type. This might be mediated by direct effects of ROS on PKC as it contains several redox-sensitive residues that can lead to PKC inactivation [52]. Proteomics data further corroborated the enhanced activation state. Interestingly, in the Ptpn22 mutant, we observed down-regulation of CENPF, a cell cycle protein that was shown to be upregulated upon TrxR inhibition [53].

Enhanced $\mathrm{T}$ cell activation led to increased inflammation in vivo and we observed a pronounced skewing towards Th1 responses. A link between PTPN22 and Th1 responses has previously been established; PTPN22\% and PTPN22 ${ }^{\mathrm{R} 619 \mathrm{~W}}$ mice accumulate Th1 effector cells in their lymphoid organs with age or upon immune challenge. Th1 expansion in these mice was 
model produced no visible differences in inflammation in PTPN22 ${ }^{\mathrm{C} 129 \mathrm{~S}}$ mice, in line with pathogenic factor in the CIA model are autoreactive B cells producing pathogenic antibodies, rather than autoreactive T cells [55].

In both T cell mediated inflammatory models (DTH and GPI) as well as on the COL2-T cell transgenic background, PTPN22 ${ }^{\mathrm{C} 129 \mathrm{~S}}$ mice displayed higher $\mathrm{T}$ cell activity as well as more regulatory T cell markers such as FOXP3 and PD1 (shown for GPI model). A rise in Treg numbers is a measure to combat inflammation, but where they originate from is a matter of discussion. They can originate from the thymus and migrate to the tissue in response to inflammation or result from conversion of $C D 4+C D 25$ - naïve $T$ cells in the periphery [56]. PTPN22 plays an important role in determining TCR signal strength during central tolerance; PTPN22-deficient mice show increased positive selection in the thymus as well as increased Treg numbers both in the thymus and periphery leading to protection from the experimental autoimmune encephalomyelitis (EAE) model of autoimmunity [18][44][45]. In our study, Treg numbers were comparable between wild-type and PTPN22 ${ }^{\mathrm{C} 129 \mathrm{~S}}$ thymi, suggesting peripheral induction of Tregs upon inflammation in PTPN22 ${ }^{\mathrm{C} 129 \mathrm{~S}}$ mice. This may be a consequence of increased IFNy production by PTPN22 ${ }^{\mathrm{C} 129 \mathrm{~S}}$ T cells as studies have also associated FOXP3 induction to Th1 responses; this mechanism links IFNy and IL27 with amplifying TGF-b-induced FOXP3 expression via STAT1 [61][62]. Previous studies have also shown the essential role of PKC- $\theta$ in NFAT-dependent FOXP3 expression. PKC- $\theta^{-/-}$mice have significantly reduced CD4+ FOXP3+

381 Tregs in the thymus, spleen and lymph nodes [51]. Accordingly, the rise in Tregs in PTPN22 ${ }^{\mathrm{C} 129 \mathrm{~S}}$ mice may be a consequence of the enhanced baseline PKC- $\theta$ signaling. 
In summary, our results show how the activity of PTPN22, a gene where a risk variant is

associated with autoimmune diseases, can be regulated by ROS through its non-catalytic C129 residue, which is likely to have a major impact on its function in addition to that of merely altered basal turnover (Fig.6D). It has been notoriously difficult to target PTPs in vivo with drug therapies due to the nature of their active sites [61], but recent advances in targeting the redox status of T lymphocytes might represent a novel strategy to treat T-cell-driven diseases. Antibody-trapping of the oxidized form of PTP1B, a highly touted drug target for diabetes and obesity, has been shown to increase insulin signaling in vitro [6][62][63]. It is therefore of importance to study the redox regulatory effects on the T cell machinery and its effects on immune processes. As such, our study contributes to the understanding of redox regulation of PTPN22 and possibly represents a new avenue for targeting PTPN22.

\section{Materials and Methods}

Recombinant expression of PTPN22 The open reading frame of human PTPN22 catalytic domain (1-303 residues), codon optimized for recombinant expression in E. coli, was synthesized by Integrated DNA Technologies, Inc. The ORF was subcloned into an in-house developed pD441b plasmid (pD441b-HsPTPN22cd) that generates a fusion protein of His6sfGFP-SUMO-HsPTPN22cd, where His6 is an N-terminal His-tag for IMAC purification, sfGPF (superfolder GFP, [64]) included for enhanced protein folding, solubility and direct visibility, and SUMO (small ubiquitin-related modifier) being a 110 residue sequence recognized by SUMO protease ULP1 that hydrolyzes the peptide bond at the C-terminus of the SUMO domain, resulting in release of the target HsPTPN22cd from its $\mathrm{N}$-terminal fusion partner. The C129S mutation of human PTPN22 was introduced into the wild-type PTPN22-encoding plasmid pD441b-HsPTPN22cd by PCR using primer pairs HsPTPN22-C129S-fwd 
HsPTPN22cd-C129S. Both plasmids were respectively transformed into E. coli BL21(DE3) strain constructs for the wild-type PTPN22cd and its C129S mutant were verified by sequencing (Eurofins Biotech). Briefly, for each protein expression and purification, a $40 \mathrm{~mL}$ overnight culture was inoculated into $2 \mathrm{~L}$ terrific broth (TB) medium containing $50 \mu \mathrm{g} / \mathrm{mL}$ kanamycin in a $5 \mathrm{~L}$-bottle placed on a shaking incubator at $37{ }^{\circ} \mathrm{C}$. Four hours after the inoculation, the incubator temperature was lowered to $25{ }^{\circ} \mathrm{C}$ and $0.5 \mathrm{mM}$ IPTG was added to induce protein expression overnight. The bacteria were harvested by centrifugation, suspended in IMAC binding buffer (50 mM Tris- $\mathrm{HCl}, 100 \mathrm{mM} \mathrm{NaCl}, 10 \mathrm{mM}$ imidazole, $\mathrm{pH}$ 7.5) and lysed by sonication. The soluble fraction was recovered by centrifugation and purified by applying a HisPrep FF 16/10 column used with an ÄKTA explorer FPLC system (Cytiva Life Sciences). The eluted and purified fusion protein was subsequently treated with an in-house expressed and purified His-tagged ULP1 ( $1 \% \mathrm{w} / \mathrm{v})$ and the cleavage solution was again re-applied onto the HisPrep FF 16/10 column for separation of non-tagged target protein from its $\mathrm{N}$-terminal Histagged fusion partner as well as from the His-tagged ULP1. The target protein was then concentrated, buffer exchanged and stored in the freezer. The purity of the product was greater than $95 \%$ as assessed by SDS-PAGE.

PTP activity assay PTP activity of recombinant wild-type PTPN22 and PTPN22 ${ }^{\mathrm{C} 1295}$ (1400nM) was measured spectrophotometrically using as substrate $15 \mathrm{mM}$ chromogenic $p$-nitrophenyl phosphate (pNPP) (P4744-1G, Sigma-Aldrich), as described previously [65]. The absorbance 


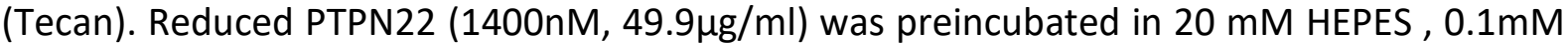
to prevent PTPN22 from time-dependent inactivation [11] together with $1 \mathrm{mM}$ sodium azide. Sodium azide was used to inhibit any trace amounts of catalase. At the indicated concentrations human Trx1, TrxR1 and NADPH (N7505-100MG, Sigma-Aldrich) were added (with Trx1 and TrxR1 expressed and purified as described in [66]. Variations in activity were observed between different batches of PTP purifications, and activities were thus always compared with the controls within each experiment.

PTP treatment with $\mathrm{H}_{2} \mathrm{O}_{2}$ and bicarbonate Pre-reduced and desalted PTPN22 was exposed to $\mathrm{H}_{2} \mathrm{O}_{2}$ and different components of the Trx system at the indicated time points followed by the addition of pNPP and measurement of activity. The activity after each $\mathrm{H}_{2} \mathrm{O}_{2}$ treatment was related to the activity of untreated PTPN22 incubated for the same time. For analysis of the effects of bicarbonate, similarly pre-reduced PTPN22 (1400nM) was pre-incubated in 20mM HEPES, $100 \mathrm{mM} \mathrm{NaCl}$ buffer, pH 7.4, containing 0.1mM EDTA, 0.05\% BSA. For treatment with oxidant, bicarbonate and $\mathrm{H}_{2} \mathrm{O} 2$ were premixed in the same buffer before addition to PTPN22 for treatment. Each PTPN22 in reaction mixture was exposed for the indicated times to $\mathrm{H}_{2} \mathrm{O}_{2}$ with or without bicarbonate $(\mathrm{pH} 7.4)$ and subsequent to this treatment, measurement of PTP activity was performed.

PTP reactivation assay PTPs from stock storage solutions were exchanged into reactivation buffer as described previously [67] containing $0.5 \%(\mathrm{v} / \mathrm{v})$ Tween 80 . Subsequently the PTPs were inactivated by treatment with $1 \mathrm{mM} \mathrm{H}_{2} \mathrm{O}_{2}$ for 5 min at $25^{\circ} \mathrm{C}$. Following this inactivation incubation, $20 \mu \mathrm{g} / \mathrm{ml}$ catalase was added to quench excess $\mathrm{H}_{2} \mathrm{O}_{2}$ whereafter the reactivation experiment was performed by adding the components of the Trx system as indicated. 
452

453

454

455

456

457

458

459

460

461

462

463

464

465

\section{Animals}

\section{Establishment of mouse strains}

Vector construction A genomic fragment encompassing exon 2 to 10 of the Ptpn 22 gene was isolated from a BAC clone of C57BL/6 origin ( $n^{\circ}$ RP23-189D14, Deutsches Ressourcenzentrum für Genomforschung). The TGT codon found in exon 5 of the Ptpn22 gene and coding for the cysteine residue present at position 129 of PTPN22 was converted into a TCC codon coding for a serine. A loxP-tACE-CRE-PGK-gb2-neor-loxP cassette (NEO;[68]) was introduced in the intron separating exons 5 and 6 of the Ptpn 22 gene, and a cassette coding for the diphtheria toxin fragment $A$ abutted to the $5^{\prime}$ end of the targeting vector.

Isolation of recombinant ES clones. After electroporation of Bruce 4 C57BL/6 ES cells [69] and selection in $\mathrm{G} 418$, colonies were screened for homologous recombination by Southern blot. A probe specific for the NEO cassette was also used to ensure that adventitious nonhomologous recombination events had not occurred in the selected ES clones.

Production of Mutant Mice. Mice were handled in accordance with national and European laws for laboratory animal welfare and experimentation (EEC Council Directive 2010/63/EU, September 2010), and protocols approved by the Marseille Ethical Committee for Animal Experimentation. Mutant Ptpn22 ${ }^{\mathrm{C} 129 \mathrm{~S}}$ ES cells were injected into FVB blastocysts. Germline transmission led to the self-excision of the NEO selection cassette in male germinal cells. Presence of the intended mutation was checked in homozygous Ptpn22 ${ }^{\mathrm{C} 129 \mathrm{~S}}$ mice by DNA sequencing. Screening of mice for the presence of the Ptpn $22^{\mathrm{C} 129 \mathrm{~S}}$ mutation was performed by PCR using the following oligonucleotides: 5'-CATGCAGGACTGTCCTCTCT-3' and 5'GTATTCTTGTCTCCCTTCCT-3'. This pair of primers amplifies a $283 \mathrm{bp}$ band in the case of the wild-type allele and a 368 bp band in the case of the Ptpn $22^{\mathrm{C} 1295}$ allele. Mice harboring the 
Ptpn22 $2^{\mathrm{C} 129 \mathrm{~S}}$ mutation have received the international strain designation $\mathrm{C} 57 \mathrm{BL} / 6$ Ptpn22 ${ }^{\text {tm1Ciphe }}$, and founders were sent to Karolinska for further experiments.

The mice were backcrossed to $\mathrm{C} 57 \mathrm{~B} 16 / \mathrm{N} . \mathrm{H} 2^{9}(\mathrm{~B} 6 \mathrm{Q})$ mice. This genetic background was used in all experiments. In some experiments we introgressed a TCR VDJ beta knock in as well as a TCR alpha locus originally derived from the DBA/1 mouse [70]. For other experiments, the $\mathrm{Ncf1}^{\mathrm{m} 1 \mathrm{j}}$ mutation was inserted, leading to a functional impairment of the NOX2 mediated ROS response [71]. Mice were kept under specific pathogen free (SPF) conditions in the animal house of the Section for Medical Inflammation Research, Karolinska Institute in Stockholm. Animals were housed in individually ventilated cages containing wood shavings in a climatecontrolled environment with a $14 \mathrm{~h}$ light-dark cycle, fed with standard chow and water ad libitum. All mice were healthy and basic physiological parameters were not affected. All the experiments were performed with age-, and sex- matched mice and in a blinded fashion. Experimental procedures were approved by the ethical committees in Stockholm, Sweden. Ethical permit numbers: 12923/18 and N134/13 (genotyping and serotyping), N35/16 (DTH, GPI, ClA).

Delayed Type Hypersensitivity (DTH). 12-week old mice were sensitized by intradermal injection of 100ug rat collagen type $\|$ (COL2) in 100ul of a 1:1 emulsion with Complete Freund's adjuvant (BD, Difco, MI, USA) and $10 \mathrm{mM}$ acetic acid at the base of the tail. Day 8 after sensitization the right ear was injected intradermally with $10 \mathrm{ul} \mathrm{COL2}$ in PBS $(1 \mathrm{mg} / \mathrm{ml})$ whilst the control left ear was injected with 10ul acetic acid in PBS. Ear swelling response was measured $0 \mathrm{~h}, 24 \mathrm{~h}, 48$ and 72 hours after challenge using a caliper. Change in ear thickness was calculated by subtracting the swelling of the PBS-injected ear from the swelling of the 
GPI-induced arthritis (GPI). Arthritis was induced by the hGPIc-c peptide (NH2-

499

500

501

502

503 IWYINCFGCETHAML-OH; Biomatik) emulsified with an equal volume of complete Freund's adjuvant. Each mouse was intradermally injected with $100 \mathrm{ul}$ emulsion (10ug/mouse) at the base of the tail and arthritis development was monitored using a macroscopic scoring system where visibly inflamed ankles or wrists received 5 points each and inflamed toes/fingers were given 1 point.

Collagen-induced arthritis (CIA). Arthritis was induced with $100 \mu \mathrm{g}$ of heterologous rat COL2 in $100 \mu \mathrm{l}$ of a 1:1 emulsion with CFA and $10 \mathrm{mM}$ acetic acid injected intradermally at the base of the tail. Mice were challenged on day 28 with $50 \mu \mathrm{g}$ of COL2 in $50 \mu$ of IFA (BD, Difco) emulsion. Arthritis development was monitored using a macroscopic scoring system as described above.

Cell culture. $10^{6}$ splenocytes or lymph node cells were cultured in $200 \mu$ l of complete DMEM per well in U-shaped bottom 96-well plates (Thermo) at $37^{\circ} \mathrm{C}$ and $5 \% \mathrm{CO}$. Complete DMEM consisted of: DMEM+Glutamax (Gibco); 5\% FBS (Gibco); $10 \mu \mathrm{M}$ HEPES (Sigma); $50 \mu \mathrm{gml}^{-1}$ streptomycin sulfate (Sigma); $60 \mu \mathrm{gml}^{-1}$ penicillin C (Sigma); $50 \mu \mathrm{M}$ beta-mercaptoethanol (Gibco). FBS was heat-inactivated for $30 \mathrm{~min}$ at $56^{\circ} \mathrm{C}$. C. Following stimuli were used: hGPIc-c

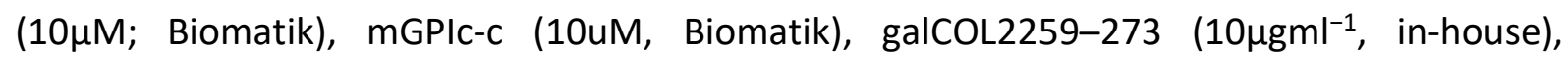
concanavalin A (ConA, 1ugml $\left.{ }^{-1}\right)$, anti-mouse CD3 (1 $\left.\mu \mathrm{gml}^{-1}, 145-2 \mathrm{C} 11, \mathrm{BD}\right)$; anti-mouse CD28 $\left(1 \mu \mathrm{gml}^{-1}, 37.51, \mathrm{BD}\right)$, Phorbol 12-myristate 13 -acetate $\left(20 \mathrm{ngml}^{-1}\right)$, ionomycin $\left(1 \mu \mathrm{gml}^{-1}\right)$

ELISA. Flat 96-well plates (Maxisorp, Nunc) were coated overnight at $4^{\circ} \mathrm{C}$ with $10 \mathrm{ug} / \mathrm{ml} \mathrm{rCOL} 2 /$ GPIp-BSA in PBS. Plates were washed in PBS+0.05\% Tween and blocked with $1 \%$ BSA in PBS for 2 hours at 37C and washed again. Mouse serum was added in dilutions varying from 1:100 to 1:10000. Plates were incubated for $2 \mathrm{~h}$ at $37 \mathrm{C}$, washed and incubated with secondary 
antibodies (Southern Biotech: IgK (1170-05), IgG2b (1091-05)) for 1hour at 37C. After washing,

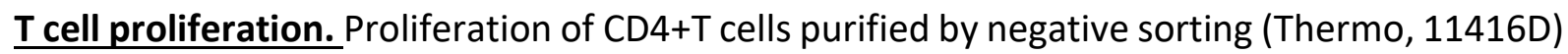

was assessed using the CellTrace Proliferation Kit (Thermo, C34554) according to

525 manufacturer's instructions.

ELISPOT. EMD Millipore MultiScreen 96-Well Assay Plates were coated overnight at $4^{\circ} \mathrm{C}$ with the capture antibody in PBS. Coating solution was decanted and $10^{6}$ splenocytes or $5 \times 10^{5}$ lymph node cells were incubated $24 \mathrm{hrs}$ at $37 \mathrm{C}$ together with various stimuli. After culture, plates were washed (0.01\% PBS-Tween) and biotinylated detection antibodies were added in PBS. Plates were washed and Extravidin Alkaline phosphatase (Sigma) was added at a 1:2500 dilution in PBS (30 min, RT). Plates were washed before adding Sigmafast BCIP/NBT (Sigma) substrate solution. Once spots became visible, plates were washed in water and spots were

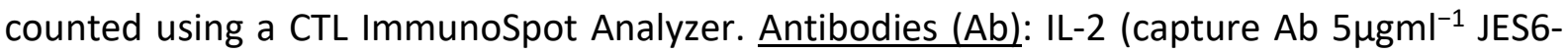
IA12; detection Ab $2 \mu \mathrm{gml}^{-1}$ biotinylated-JES6-5H4, in-house produced); IL-17A (capture Ab 5

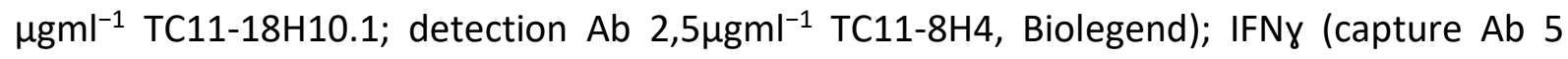
$\mathrm{ggml}^{-1}$ AN18; detection Ab 2,5 $\mathrm{\mu gml}^{-1}$ biotinylated R46A2, in-house produced).

qPCR RNA was extracted from $1-2 \times 10^{6}$ cells using Qiagen RNeasy columns according to the (Thermo Scientific) and sample concentrations were normalized before proceeding with reverse transcription. cDNA synthesis was carried out using the iScript cDNA synthesis kit

541 (BioRad) according to manufacturer's instructions. The qPCR reaction was carried out using 
system (BioRad). Actb was used as an endogenous control. Data were analyzed according to the $\Delta \Delta \mathrm{Ct}$ method [73]. Primer sequences are listed in supplemental table 1.

Flow cytometry Samples were stained with the indicated antibodies in $50 \mu \mathrm{l}$ of PBS diluted

1:200 at $4^{\circ} \mathrm{C}$ for $20 \mathrm{~min}$ in the dark. Cells were washed once, fixed and permeabilized for

intracellular staining using $\mathrm{BD}$ Cytofix/Cytoperm ${ }^{\mathrm{TM}}$ (BD) according to manufacturer's

instructions. Cell were stained intracellularly with $50 \mu \mathrm{l}$ of permeabilization buffer (BD), using

the antibodies at a 1:100 final dilution, for $20 \mathrm{~min}$ at RT. FoxP3 staining required nuclear

Buffer. For intracellular cytokine staining, cells were stimulated in vitro with phorbol 12prior to fixation, permeabilization and staining. Antibodies are listed in supplemental table 2 .

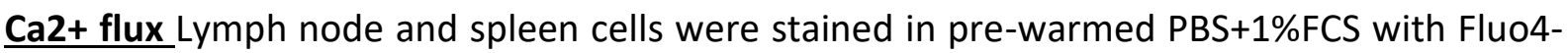
AM (2uM, Thermo) and FuraRed AM (4uM, Thermo) at 37C. Cells were washed in cold PBS+1\%FCS before staining for extracellular markers for 20 mins. Baseline Ca2+ flux was recorded for 100 s before $50 \mathrm{ul}$ anti-CD3 (10ug/ml; BD) stimulation was added; after 5 minutes, maximum flux was measured using ionomycin (1ug/ml; BD). Relative calcium concentration was plotted as ratio of Fluo3 to FuroRed emission using FlowJo.

Protein isolation and SDS-PAGE Total protein was isolated from $2 \times 10^{6}$ cells in $60 \mu$ l lysis buffer (M-PER, Thermo) with freshly added protease inhibitors (Halt cocktail 100x, Thermo). Lysates were centrifuged for $10 \mathrm{~min}$ at top speed and protein concentrations of supernatants were measured using Pierce BCA Protein Assay Kit (Thermo, 23225). SDS-PAGE (4-12\% NuPAGE BisMOPS buffer). 
Western blot Proteins were blotted onto a PVDF membrane (Millipore) for $1,5 \mathrm{~h}$ at $35 \mathrm{~V}$ in

567

568

NuPAGE transfer buffer (Thermo Fisher). Membranes were blocked for $1 \mathrm{~h}$ at RT in blocking solution (0.05\% PBS-Tween, 5\% BSA). Incubation with primary antibodies (listed below) was performed overnight at $4^{\circ} \mathrm{C}$ in blocking solution. After incubation, membranes were washed in PBS-T and incubated with Affinipure peroxidase-coupled goat anti-rabbit $\lg G(\mathrm{H}+\mathrm{L})$ (final conc. $40 \mathrm{ngml}^{-1}$, Jackson laboratories) for $1 \mathrm{~h}$ at RT. Membranes were washed and coated with ECL substrate solution (GE Healthcare) before imaging on a ChemiDoc XRS+ (BioRad). Antibodies Cell Signaling Technology: p-PKC (9377S), PKC (1364S), Zap70 (2705S), PTPN22 (14693S), p-Src (2101S), LCK (2752S), Fyn (4023S), H2B (12364s) Abcam: p-Zap70 (ab194800), actin (ab8227), vinculin (ab129002)

LC-MS sample preparation. For proteomics analysis, cells were collected after treatment, washed twice with PBS, and then lysed using $8 \mathrm{M}$ urea, 1\% SDS, and 50mM Tris at $\mathrm{pH} 8.5$ with protease inhibitors (Sigma; Cat\#05892791001). The cell lysates were subjected to $1 \mathrm{~min}$ sonication on ice using Branson probe sonicator and $3 \mathrm{~s}$ on/off pulses with a $30 \%$ amplitude. Protein concentration was then measured for each sample using a BCA Protein Assay Kit (Thermo; Cat\#23227). $6.8 \mu \mathrm{g}$ of each sample was reduced with DTT (final concentration 10mM) (Sigma; Cat\#D0632) for $1 \mathrm{~h}$ at room temperature. Afterwards, iodoacetamide (IAA) (Sigma; Cat\#16125) was added to a final concentration of 50mM. The samples were incubated at room temperature for $1 \mathrm{~h}$ in the dark, with the reaction being stopped by addition of $10 \mathrm{mM}$ DTT. After precipitation of proteins using methanol/chloroform, the semi-dry protein pellet was dissolved in $25 \mu \mathrm{L}$ of $8 \mathrm{M}$ urea in 20mM EPPS (pH 8.5) (Sigma; Cat\#E9502) and was then diluted with EPPS buffer to reduce urea concentration to $4 \mathrm{M}$. Lysyl endopeptidase (LysC) (Wako; Cat\#125-05061) was added at a $1: 75 \mathrm{w} / \mathrm{w}$ ratio to protein and incubated at room temperature overnight. After diluting urea to $1 \mathrm{M}$, trypsin (Promega; Cat\#V5111) was added 
at the ratio of $1: 75 \mathrm{w} / \mathrm{w}$ and the samples were incubated for $6 \mathrm{~h}$ at room temperature.

591

592

593

594

595 Acetonitrile (Fisher Scientific; Cat\#1079-9704) was added to a final concentration of $20 \% \mathrm{v} / \mathrm{v}$. TMTpro reagents (Thermo; Cat\#90110) were added $4 \mathrm{x}$ by weight to each sample, followed by incubation for $2 \mathrm{~h}$ at room temperature. The reaction was quenched by addition of $0.5 \%$ hydroxylamine (Thermo Fisher; Cat\#90115). Samples were combined, acidified by trifluoroacetic acid (TFA; Sigma; Cat\#302031-M), cleaned using Sep-Pak (Waters; Cat\#WAT054960) and dried using a DNA 120 SpeedVac $^{\text {TM }}$ concentrator (Thermo). Samples were then resuspended in $20 \mathrm{mM}$ ammonium hydroxide and separated into 96 fractions on an XBrigde BEH C18 $2.1 \times 150 \mathrm{~mm}$ column (Waters; Cat\#186003023), using a Dionex Ultimate 3000 2DLC system (Thermo Scientific) over a $48 \mathrm{~min}$ gradient of $1-63 \% B \quad(B=20 \mathrm{mM}$ ammonium hydroxide in acetonitrile) in three steps (1-23.5\%B in $42 \mathrm{~min}, 23.5-54 \% \mathrm{~B}$ in $4 \mathrm{~min}$

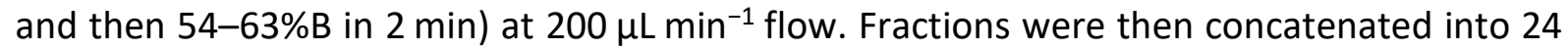
samples in sequential order (e.g. 1, 25, 49, 73). After drying and resuspension in $0.1 \%$ formic acid (FA) (Fisher Scientific), each fraction was analyzed with a 90 min gradient in random order.

LC-MS analysis. Samples were loaded with buffer A (0.1\% FA in water) onto a $50 \mathrm{~cm}$ EASYSpray column (75 $\mu \mathrm{m}$ internal diameter, packed with PepMap C18, $2 \mu \mathrm{m}$ beads, $100 \AA ̊$ pore size) connected to a nanoflow Dionex UltiMate 3000 UPLC system (Thermo) and eluted in an increasing organic solvent gradient from 4 to $28 \%\left(\mathrm{~B}\right.$ : $98 \% \mathrm{ACN}, 0.1 \% \mathrm{FA}, 2 \% \mathrm{H}_{2} \mathrm{O}$ ) at a flow rate of $300 \mathrm{nLmin}^{-1}$. Mass spectra were acquired with an orbitrap Fusion Lumos mass spectrometer (Thermo) in the data-dependent mode with MS1 scan at 120,000 resolution, and MS2 at $50,000(@ 200 \mathrm{~m} / \mathrm{z})$, in the mass range from 400 to $1600 \mathrm{~m} / \mathrm{z}$. Peptide fragmentation was performed via higher-energy collision dissociation (HCD) with energy set at 35 NCE. 
614 Protein identification and quantification. The raw data from LC-MS were analyzed by MaxQuant, version 1.6.2.3 [74]. The Andromeda engine [75] searched MS/MS data against UniProt complete proteome database (Mus musculus, version UP000000589, 22,137 entries). and protein $\mathrm{N}$-terminal acetylation were selected as a variable modification. Trypsin/P was selected as enzyme specificity. No more than two missed cleavages were allowed. A $1 \%$ false discovery rate was used as a filter at both protein and peptide levels. First search tolerance was 20ppm (default) and main search tolerance was $4.5 \mathrm{ppm}$ (default), and the minimum peptide length was 7 residues. After removing all the contaminants, only proteins with at least two unique peptides were included in the final dataset. Protein abundances were normalized by the total protein abundance in each sample in deep datasets. In the original dataset, protein abundances were normalized to ensure same median abundance across all channels $\log 2$-ratio of the intensity to the median of all control replicates. All the proteins quantified in each experiment were used as the background.

Statistical analysis. Statistical analysis was performed using GraphPad Prism v6.0. Statistical comparison of two unpaired groups was carried out using Mann-Whitney U non-parametric test unless stated otherwise. Welch's variant of the Student t-test was used in indicated experiments. P-values under 0.05 were considered statistically significant and are denoted as $*(p<0.05)$ or $* *(p<0.01)$.

[1] J. Ye, K. M. Gillespie, and S. Rodriguez, "Unravelling the roles of susceptibility loci for autoimmune diseases in the post-GWAS era," Genes, vol. 9, no. 8. MDPI AG, 01-Aug2018. with type I diabetes," Nat. Genet., vol. 36, no. 4, pp. 337-338, Apr. 2004. 
[3] L. M. Olsson et al., "Copy number variation of the gene NCF1 is associated with rheumatoid arthritis," Antioxidants Redox Signal., vol. 16, no. 1, pp. 71-78, Jan. 2012.

[4] L. M. Olsson et al., "A single nucleotide polymorphism in the NCF1 gene leading to reduced oxidative burst is associated with systemic lupus erythematosus," Ann. Rheum. Dis., vol. 76, no. 9, pp. 1607-1613, Sep. 2017.

[5] N. Bottini and E. J. Peterson, "Tyrosine Phosphatase PTPN22: Multifunctional Regulator of Immune Signaling, Development, and Disease," Annu. Rev. Immunol., vol. 32, no. 1, pp. 83-119, Mar. 2014.

[6] S. M. Stanford and N. Bottini, "PTPN22: the archetypal non-HLA autoimmunity gene.," Nat. Rev. Rheumatol., vol. 10, no. 10, pp. 602-611, 2014.

[7] F. D. Carmona and J. Martín, "The potential of PTPN22 as a therapeutic target for rheumatoid arthritis," Expert Opin. Ther. Targets, vol. 22, no. 10, pp. 879-891, Oct. 2018.

[8] P. Kesarwani, A. K. Murali, A. A. Al-Khami, and S. Mehrotra, "Redox regulation of T-cell function: from molecular mechanisms to significance in human health and disease.," Antioxid. Redox Signal., vol. 18, no. 12, pp. 1497-534, 2013.

[9] A. Östman, J. Frijhoff, Å. Sandin, and F.-D. Böhmer, "Regulation of protein tyrosine phosphatases by reversible oxidation," J. Biochem., vol. 150, no. 4, pp. 345-356, 2011.

[10] S. J. Tsai et al., "Crystal structure of the human lymphoid tyrosine phosphatase catalytic domain: Insights into redox regulation," Biochemistry, vol. 48, no. 22, pp. 4838-4845, 2009.

[11] M. Dagnell et al., "Bicarbonate is essential for protein-tyrosine phosphatase 1B (PTP1B) oxidation and cellular signaling through EGF-triggered phosphorylation cascades," Journal of Biological Chemistry, vol. 294, no. 33. American Society for Biochemistry and Molecular Biology Inc., pp. 12330-12338, 16-Aug-2019.

[12] M. Dagnell, Q. Cheng, and E. S. J. Arnér, "Qualitative differences in protection of ptp1b activity by the reductive trx1 or trp14 enzyme systems upon oxidative challenges with polysulfides or h2o2 together with bicarbonate," Antioxidants, vol. 10, no. 1, pp. 1-12, Jan. 2021.

[13] M. Dagnell et al., "Selective activation of oxidized PTP1B by the thioredoxin system modulates PDGF-ß receptor tyrosine kinase signaling," Proc. Natl. Acad. Sci. U. S. A., vol. 110, no. 33, pp. 13398-13403, Aug. 2013.

[14] U. Schwertassek et al., "Reactivation of oxidized PTP1B and PTEN by thioredoxin 1," FEBS J., vol. 281, no. 16, pp. 3545-3558, Aug. 2014.

[15] U. Brunsberg et al., "Expression of a transgenic class II Ab gene confers susceptibility to collagen-induced arthritis," Eur. J. Immunol., vol. 24, no. 7, pp. 1698-1702, 1994.

[16] M. Hultqvist, P. Olofsson, J. Holmberg, B. T. Bäckström, J. Tordsson, and R. Holmdahl, "Enhanced autoimmunity, arthritis, and encephalomyelitis in mice with a reduced oxidative burst due to a mutation in the Ncf1 gene," Proc. Natl. Acad. Sci. U. S. A., vol. 101, no. 34, pp. 12646-12651, Aug. 2004. 
[17] I. C. Allen, "Delayed-Type Hypersensitivity Models in Mice," in Mouse Models of Innate Immunity: Methods and Protocols, I. C. Allen, Ed. Totowa, NJ: Humana Press, 2013, pp. 101-107.

[18] P. Olofsson, J. Holmberg, J. Tordsson, S. Lu, B. Åkerström, and R. Holmdahl, "Positional identification of Ncf1 as a gene that regulates arthritis severity in rats," Nat. Genet., vol. 33, no. 1, pp. 25-32, Jan. 2003.

[19] P. Merky et al., "Visualization and phenotyping of proinflammatory antigen-specific T cells during collagen-induced arthritis in a mouse with a fixed collagen type II-specific transgenic T-cell receptor $\beta$-chain," Arthritis Res. Ther., vol. 12, no. 4, 2010.

[20] A. Pizzolla, K. Wing, and R. Holmdahl, "A glucose-6-phosphate isomerase peptide induces $\mathrm{T}$ and $\mathrm{B}$ cell-dependent chronic arthritis in $\mathrm{C} 57 \mathrm{bl} / 10$ mice: Arthritis without reactive oxygen species and complement," Am. J. Pathol., vol. 183, no. 4, pp. 11441155, Oct. 2013.

[21] A. Pizzolla, F. Laulund, K. Wing, and R. Holmdahl, "A new model of arthritis induced by a glucose-6-phosphate isomerase peptide: immunological requirements and peptide characterisation," Ann. Rheum. Dis., vol. 71, no. Suppl 1, p. A83.2-A83, Feb. 2012.

[22] C. J. Maine et al., "PTPN22 Alters the Development of Regulatory T Cells in the Thymus," J. Immunol., vol. 188, no. 11, pp. 5267-5275, Jun. 2012.

[23] R. J. Salmond, R. J. Brownlie, V. L. Morrison, and R. Zamoyska, "The tyrosine phosphatase PTPN22 discriminates weak self peptides from strong agonist TCR signals," Nat Immunol, vol. 15, no. 9, pp. 875-883, 2014.

[24] P. C. Baciu, S. Saoncella, S. H. Lee, F. Denhez, D. Leuthardt, and P. F. Goetinck, "Syndesmos, a protein that interacts with the cytoplasmic domain of syndecan-4, mediates cell spreading and actin cytoskeletal organization," J. Cell Sci., vol. 113, no. 2, pp. 315-324, 2000.

[25] F. Denhez et al., "Syndesmos, a syndecan-4 cytoplasmic domain interactor, binds to the focal adhesion adaptor proteins paxillin and Hic-5," J. Biol. Chem., vol. 277, no. 14, pp. 12270-12274, Apr. 2002.

[26] K. S. Suh et al., "CLIC4 mediates and is required for Ca2+-induced keratinocyte differentiation," J. Cell Sci., vol. 120, no. 15, pp. 2631-2640, Aug. 2007.

[27] I. Boldogh et al., "Regulation of Expression of the DNA Repair Gene O6Methylguanine-DNA Methyltransferase via Protein Kinase C-mediated Signaling," Cancer Res., vol. 58, no. 17, 1998.

[28] T. Koliński, N. Marek-Trzonkowska, P. Trzonkowski, and J. Siebert, "Heat shock proteins (HSPs) in the homeostasis of regulatory T cells (Tregs)," Central European Journal of Immunology, vol. 41, no. 3. Termedia Publishing House Ltd., pp. 317-323, 2016.

[29] S. Janciauskiene et al., "Alpha1-antitrypsin binds hemin and prevents oxidative activation of human neutrophils: putative pathophysiological significance," J. Leukoc. Biol., vol. 102, no. 4, pp. 1127-1141, Oct. 2017. 
[30] Z. Liu, G. Ning, R. Xu, Y. Cao, A. Meng, and Q. Wang, "Fscn1 is required for the trafficking of TGF- $\beta$ family type i receptors during endoderm formation," Nat. Commun., vol. 7, Aug. 2016.

[31] G. Vecchio et al., "Human $\alpha$-L-fucosidase-1 attenuates the invasive properties of thyroid cancer," Oncotarget, vol. 8, no. 16, pp. 27075-27092, 2017.

[32] A. Romanelli, K. A. Martin, A. Toker, and J. Blenis, "p70 S6 Kinase Is Regulated by Protein Kinase $\mathrm{C} \zeta$ and Participates in a Phosphoinositide 3-Kinase-Regulated Signalling Complex," Mol. Cell. Biol., vol. 19, no. 4, pp. 2921-2928, Apr. 1999.

[33] H. Sies and D. P. Jones, "Reactive oxygen species (ROS) as pleiotropic physiological signalling agents," Nature Reviews Molecular Cell Biology, vol. 21, no. 7. Nature Research, pp. 363-383, 01-Jul-2020.

[34] E. S. J. Arnér and A. Holmgren, "Physiological functions of thioredoxin and thioredoxin reductase," European Journal of Biochemistry, vol. 267, no. 20. Eur J Biochem, pp. 6102-6109, 2000.

[35] M. Schieber and N. S. Chandel, "ROS function in redox signaling and oxidative stress," Current Biology, vol. 24, no. 10. Cell Press, 19-May-2014.

[36] J. Zhong, L. M. Olsson, V. Urbonaviciute, M. Yang, L. Bäckdahl, and R. Holmdahl, "Association of NOX2 subunits genetic variants with autoimmune diseases," Free Radic. Biol. Med., vol. 125, no. March, pp. 72-80, 2018.

[37] T. Kelkka et al., "Reactive oxygen species deficiency induces autoimmunity with type 1 interferon signature," Antioxidants Redox Signal., vol. 21, no. 16, pp. 2231-2245, Dec. 2014.

[38] R. L. Contento, S. Campello, A. E. Trovato, E. Magrini, F. Anselmi, and A. Viola, "Adhesion shapes T cells for prompt and sustained T-cell receptor signalling," EMBO J., vol. 29, no. 23, pp. 4035-4047, Dec. 2010.

[39] K. A. Gelderman et al., "Macrophages suppress T cell responses and arthritis development in mice by producing reactive oxygen species," J. Clin. Invest., vol. 117, no. 10, pp. 3020-3028, Oct. 2007.

[40] D. G. Franchina, C. Dostert, and D. Brenner, "Reactive Oxygen Species: Involvement in T Cell Signaling and Metabolism," Trends in Immunology, vol. 39, no. 6. Elsevier Ltd, pp. 489-502, 01-Jun-2018.

[41] R. Brigelius-Flohé and L. Flohé, "Basic principles and emerging concepts in the redox control of transcription factors," Antioxidants and Redox Signaling, vol. 15, no. 8. Antioxid Redox Signal, pp. 2335-2381, 15-Oct-2011.

[42] S. García-Santamarina, S. Boronat, and E. Hidalgo, "Reversible cysteine oxidation in hydrogen peroxide sensing and signal transduction," Biochemistry, vol. 53, no. 16, pp. 2560-2580, Apr. 2014.

[43] R. D. Michalek et al., "The Requirement of Reversible Cysteine Sulfenic Acid Formation for T Cell Activation and Function," J. Immunol., vol. 179, no. 10, pp. 6456-6467, Nov. 2007. 
[44] J. Frijhoff, M. Dagnell, R. Godfrey, and A. Östman, "Regulation of protein tyrosine phosphatase oxidation in cell adhesion and migration," Antioxidants and Redox Signaling, vol. 20, no. 13. Mary Ann Liebert Inc., pp. 1994-2010, 01-May-2014.

[45] N. K. Tonks, "PTP1B: From the sidelines to the front lines!," FEBS Letters, vol. 546, no. 1. Elsevier, pp. 140-148, 03-Jul-2003.

[46] Dóka et al., "Control of protein function through oxidation and reduction of persulfidated states," Sci. Adv., vol. 6, no. 1, Jan. 2020.

[47] M. Dagnell et al., "Thioredoxin reductase 1 and NADPH directly protect protein tyrosine phosphatase 1B from inactivation during $\mathrm{H} 2 \mathrm{O} 2$ exposure," J. Biol. Chem., vol. 292, no. 35, pp. 14371-14380, Sep. 2017.

[48] F. D. Carmona and J. Martín, "The potential of PTPN22 as a therapeutic target for rheumatoid arthritis," Expert Opinion on Therapeutic Targets, vol. 22, no. 10. Taylor and Francis Ltd, pp. 879-891, 03-Oct-2018.

[49] X. Wang, H.-C. Chuang, J.-P. Li, and T.-H. Tan, "Regulation of PKC- $\theta$ function by phosphorylation in T cell receptor signaling," Front. Immunol., vol. 3, no. JUL, p. 197, Jul. 2012.

[50] V. Brezar, W. J. Tu, and N. Seddiki, "PKC-theta in regulatory and effector T-cell functions," Frontiers in Immunology, vol. 6, no. OCT. Frontiers Media S.A., p. 1, 13Oct-2015.

[51] S. Gupta, S. Manicassamy, C. Vasu, A. Kumar, W. Shang, and Z. Sun, "Differential requirement of PKC- $\theta$ in the development and function of natural regulatory T cells," Mol. Immunol., vol. 46, no. 2, pp. 213-224, Dec. 2008.

[52] S. F. Steinberg, "Mechanisms for redox-regulation of protein kinase C," Frontiers in Pharmacology, vol. 6, no. JUN. Frontiers Research Foundation, 2015.

[53] M. Selenius et al., "Effects of redox modulation by inhibition of thioredoxin reductase on radiosensitivity and gene expression," J. Cell. Mol. Med., vol. 16, no. 7, pp. 15931605, Jul. 2012.

[54] C. Sanchez-Blanco et al., "Protein tyrosine phosphatase PTPN22 regulates LFA-1 dependent Th1 responses," J. Autoimmun., vol. 94, pp. 45-55, Nov. 2018.

[55] R. Holmdahl, M. Andersson, T. J. Goldschmidt, K. E. Gustafsson, L. Jansson, and J. A. Mo, "Type II Collagen Autoimmunity in Animals and Provocations Leading to Arthritis," Immunol. Rev., vol. 118, no. 1, pp. 193-232, 1990.

[56] M. Yadav, S. Stephan, and J. A. Bluestone, "Peripherally induced Tregs-role in immune homeostasis and autoimmunity," Front. Immunol., vol. 4, no. AUG, 2013.

[57] K. Hasegawa, F. Martin, G. Huang, D. Tumas, L. Diehl, and A. C. Chan, "PEST DomainEnriched Tyrosine Phosphatase (PEP) Regulation of Effector/Memory T Cells," Science (80-. )., vol. 303, no. 5658, pp. 685-689, Jan. 2004.

[58] G. Fousteri et al., "The protein tyrosine phosphatase PTPN22 controls forkhead box protein $3 \mathrm{~T}$ regulatory cell induction but is dispensable for T helper type 1 cell polarization," Clin. Exp. Immunol., vol. 178, no. 1, pp. 178-189, 2014. 
[59] N. Ouaked et al., " Regulation of the foxp3 Gene by the Th1 Cytokines: The Role of IL27-Induced STAT1 ," J. Immunol., vol. 182, no. 2, pp. 1041-1049, Jan. 2009.

[60] K. Littringer et al., "Common features of regulatory T cell specialization during Th1 responses," Front. Immunol., vol. 9, no. JUN, p. 1344, Jun. 2018.

[61] S. M. Stanford and N. Bottini, "Targeting Tyrosine Phosphatases: Time to End the Stigma," Trends Pharmacol. Sci., vol. 38, no. 6, 2017.

[62] N. Krishnan et al., "Harnessing insulin-and leptin-induced oxidation of PTP1B for therapeutic development," Nat. Commun., vol. 9, no. 1, pp. 1-17, Dec. 2018.

[63] S. M. Stanford and N. Bottini, "Targeting Tyrosine Phosphatases: Time to End the Stigma," Trends in Pharmacological Sciences, vol. 38, no. 6. Elsevier Ltd, pp. 524-540, 01-Jun-2017.

[64] J. D. Pédelacq, S. Cabantous, T. Tran, T. C. Terwilliger, and G. S. Waldo, "Engineering and characterization of a superfolder green fluorescent protein," Nat. Biotechnol., vol. 24, no. 1, pp. 79-88, Jan. 2006.

[65] J. Montalibet, K. I. Skorey, and B. P. Kennedy, "Protein tyrosine phosphatase: Enzymatic assays," Methods, vol. 35, no. 1, pp. 2-8, Jan. 2005.

[66] Q. Cheng and E. S. J. Arnér, "Selenocysteine insertion at a predefined UAG codon in a release factor 1 (RF1)-depleted Escherichia coli Host strain bypasses species barriers in recombinant selenoprotein translation," J. Biol. Chem., vol. 292, no. 13, pp. 54765487, Mar. 2017.

[67] Z. D. Parsons and K. S. Gates, "Thiol-dependent recovery of catalytic activity from oxidized protein tyrosine phosphatases," Biochemistry, vol. 52, no. 37, pp. 6412-6423, Sep. 2013.

[68] M. Mingueneau et al., "The proline-rich sequence of $C D 3 \varepsilon$ controls T cell antigen receptor expression on and signaling potency in preselection CD4+CD8+ thymocytes," Nat. Immunol., vol. 9, no. 5, pp. 522-532, May 2008.

[69] F. Köntgen, G. Süss, C. Stewart, M. Steinmetz, and H. Bluethmann, "Targeted disruption of the MHC class II Aa gene in C57BL/6 mice," Int. Immunol., vol. 5, no. 8, pp. 957-964, Aug. 1993.

[70] L. Mori, H. Loetscher, K. Kakimoto, H. Bluethmann, and M. Steinmetz, "Expression of a transgenic T cell receptor/ $\beta$ chain enhances collagen-induced arthritis," J. Exp. Med., vol. 176, no. 2, pp. 381-388, Aug. 1992.

[71] O. Sareila, N. Jaakkola, P. Olofsson, T. Kelkka, and R. Holmdahl, "Identification of a region in p47phox/NCF1 crucial for phagocytic NADPH oxidase (NOX2) activation," J. Leukoc. Biol., vol. 93, no. 3, pp. 427-435, Mar. 2013.

[72] L. Mac-Daniel, M. R. Buckwalter, P. Gueirard, and R. Ménard, "Myeloid cell isolation from mouse skin and draining lymph node following intradermal immunization with live attenuated Plasmodium sporozoites," J. Vis. Exp., vol. 2016, no. 111, p. 53796, May 2016.

[73] K. J. Livak and T. D. Schmittgen, "Analysis of Relative Gene Expression Data Using Real- 
Time Quantitative PCR and the 2- $\Delta \Delta C T$ Method," Methods, vol. 25, no. 4, pp. 402408, Dec. 2001.

[74] J. Cox and M. Mann, "MaxQuant enables high peptide identification rates, individualized p.p.b.-range mass accuracies and proteome-wide protein quantification," Nat. Biotechnol., 2008.

[75] J. Cox, N. Neuhauser, A. Michalski, R. A. Scheltema, J. V. Olsen, and M. Mann, "Andromeda: A peptide search engine integrated into the MaxQuant environment," J. Proteome Res., 2011.

[76] J. A. Vizcaíno et al., "ProteomeXchange provides globally coordinated proteomics data submission and dissemination," Nature Biotechnology, vol. 32, no. 3. Nature Publishing Group, pp. 223-226, 2014.

[77] A. Bajnok, A. Kaposi, L. Kovács, B. Vásárhelyi, A. Balog, and G. Toldi, “Analysis by flow cytometry of calcium influx kinetics in peripheral lymphocytes of patients with rheumatoid arthritis," Cytom. Part A, vol. 83A, no. 3, pp. 287-293, Mar. 2013.

[78] D. Davidson et al., "The Csk-Associated Adaptor PAG Inhibits Effector T Cell Activation in Cooperation with Phosphatase PTPN22 and Dok Adaptors," Cell Rep., vol. 17, no. 10, pp. 2776-2788, Dec. 2016.

\section{Data availability}

The mass spectrometry data that support the findings of this study have been deposited in ProteomeXchange Consortium (https://www.ebi.ac.uk/pride/) via the PRIDE partner repository [76] with the dataset identifiers PXD025319.

\section{Acknowledgements}

This work was supported by grants from the Knut and Alice Wallenberg foundation, the Swedish Medical Research Council, the Swedish Foundation for Strategic Research, the Hungarian Thematic Excellence Programme (TKP2020-NKA-26), and AstraZeneca. We thank F. Fiore for the construction of the Ptpn $22^{\mathrm{C} 129 S}$ mice. The work performed at Centre d'Immunophénomique was supported in part by the Investissement d'Avenir program PHENOMIN (ANR-10-INBS-07, to B.M.). 


\section{Author contributions}

$872 \mathrm{JJ}$ planned and performed data involving the mouse work, analyzed the data and wrote the

873 first draft of the manuscript. B.M. conceived and developed the Ptpn222 ${ }^{\mathrm{C} 129 \mathrm{~S}}$ mice. FF and CMH

874 contributed to the initial steps of the project. YC performed the analysis of the recombinant

875 PTPN22 molecules. QC, MD and EA designed, planned and supervised the work and analysis

876 of the recombinant PTPN22 proteins and EA made critical contributions to the writing of the

877 manuscript. AAS, MG, and RZ contributed with mass spectrometry data. Å and RM

878 contributed to the planning and supervision of the project. All authors revised and approved

879 the manuscript. R.H. planned and supervised the project and takes the overall responsibility.

880 Competing interest: The authors declare no competing interests. The data that support the

881 findings of this study are available from the corresponding author upon reasonable request. 
bioRxiv preprint doi: https://doi.org/10.1101/2021.12.02 470976; this version posted December 6, 2021. The copyright holder for this preprint (which was not certified by peer review) is the author/funder, who has granted bioRxiv a license to display the preprint in perpetuity. It is made available under aCC-BY 4.0 International license.
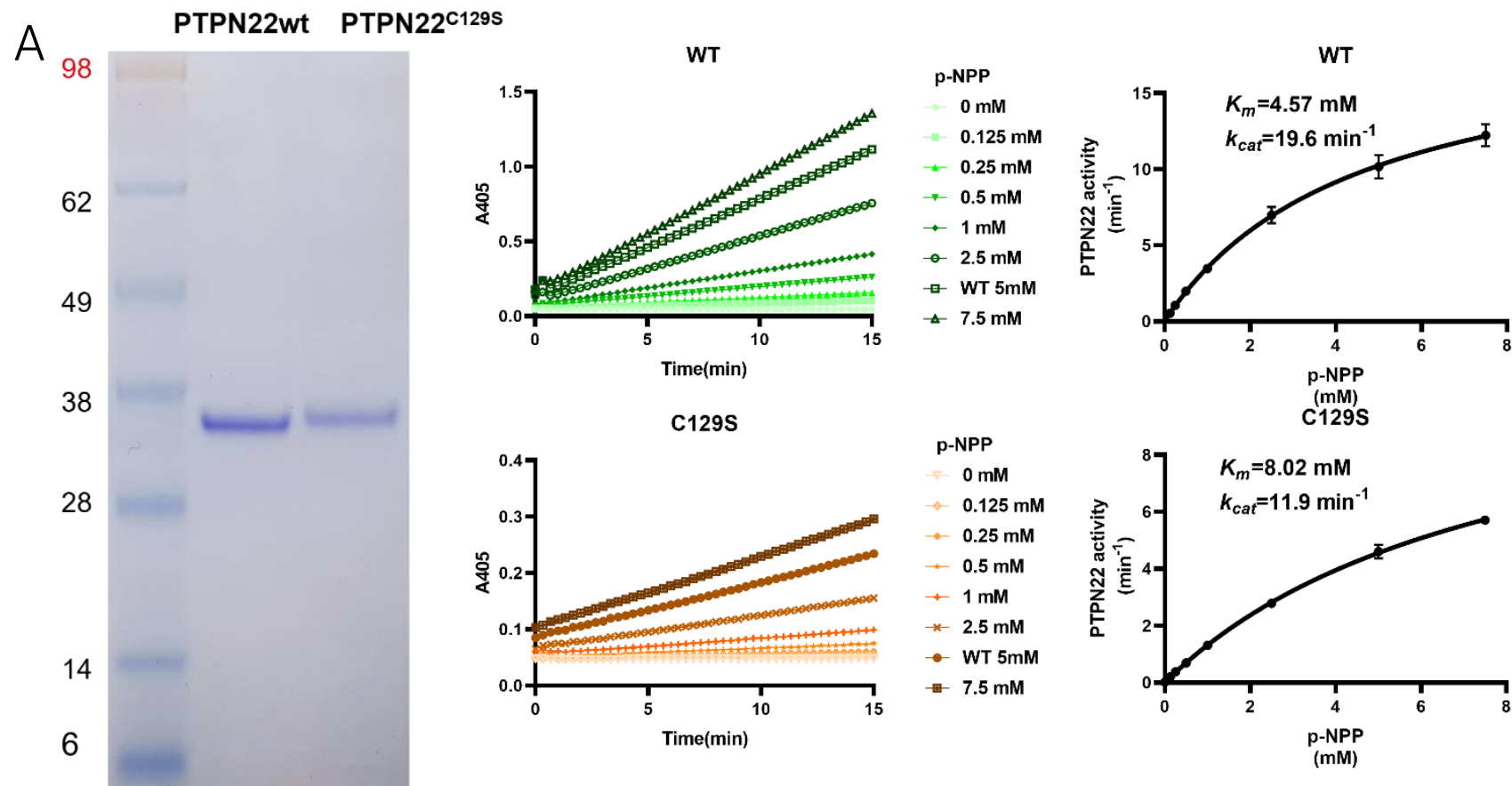

B
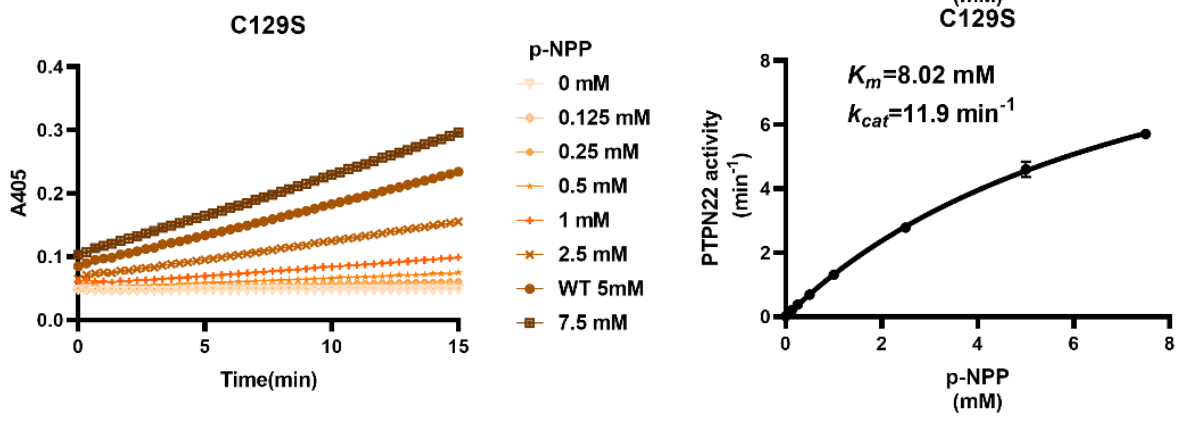

C

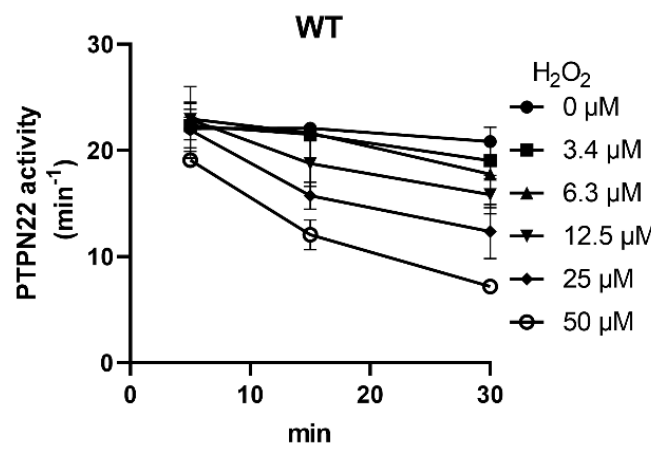

D

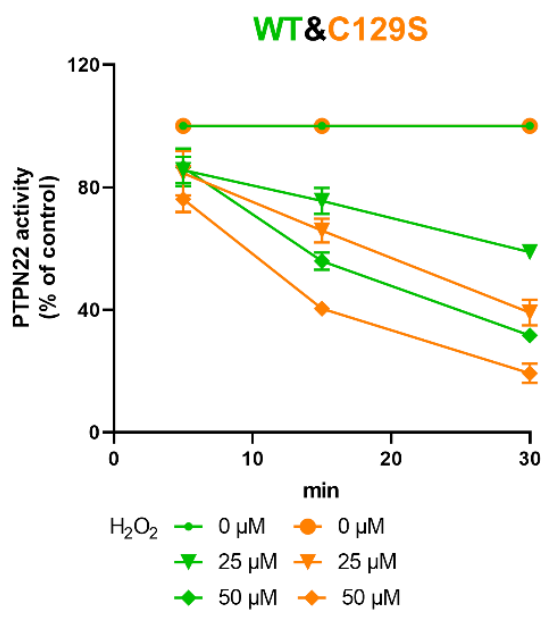

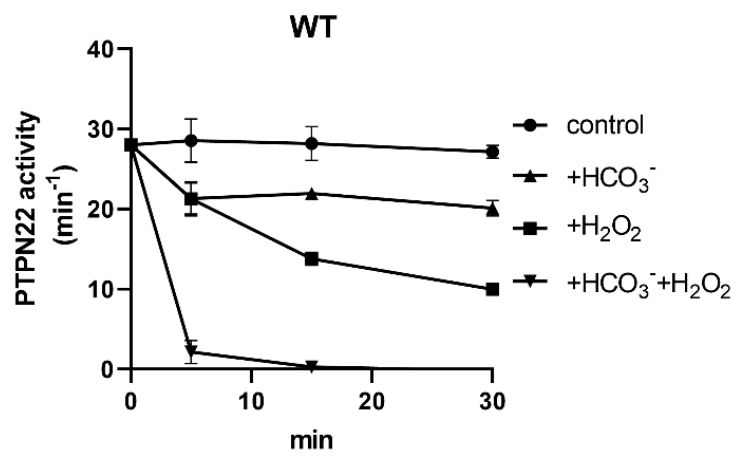

$\mathrm{E}$

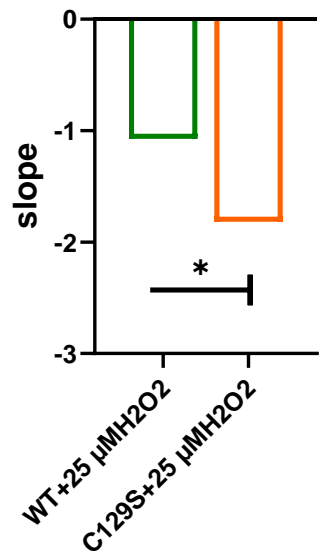


bioRxiv preprint doi: https://doi.org/10.1101/2021.12.02.470976; this version posted December 6,2021 . The copyright holder for this preprint (which was not certified by peer review) is the author/funder, who has granted bioRxiv a license to display the preprint in perpetuity. It is made available under aCC-BY 4.0 International license.

Fig.1. PTPN22 ${ }^{\mathrm{C} 1295}$ is more prone to oxidative inactivation. A) Purified human wild-type and PTPN22 ${ }^{\mathrm{C} 1295}$ proteins are shown as analyzed on SDS-PAGE, and kinetic parameters were measured using $p$-NPP as substrate as shown to the right. Data points represent mean \pm S.D. (error bars) $(n=3)$. B) PTPN22 (1400nM) was treated with indicated concentrations of $\mathrm{H}_{2} \mathrm{O}_{2}$ and then assayed for PTP activity at the indicated times. PTPN22 activity is given in $\mathrm{min}^{-1}$ (mol of product $/ \mathrm{mol}$ of enzyme/min). Data points represent mean \pm S.D. (error bars) ( $\mathrm{n}=3$ ). C) PTPN22 (1400nM) activity was measured as in $A$ but with buffer control $(\bullet), 25 \mathrm{mM}$ bicarbonate $(\boldsymbol{\Delta}), 30 \mu \mathrm{M} \mathrm{H}_{2} \mathrm{O}_{2}(\boldsymbol{\bullet})$ or the combination of $30 \mu \mathrm{M} \mathrm{H}_{2} \mathrm{O}_{2}$ and $25 \mathrm{mM}$ bicarbonate $(\boldsymbol{\nabla})$. Data points represent mean \pm S.D. (error bars) $(n=4)$. D) Wild-type (green) and PTPN22 ${ }^{\mathrm{C} 2295}$ (orange) proteins were treated with indicated $\mathrm{H}_{2} \mathrm{O}_{2}$ concentrations and then assayed for PTP activity. Data points represent mean \pm S.D. (error bars) $(n=3)$ and activities are given as $\%$ of buffer control for each enzyme. E) Pre-reduced wild-type (green) and PTPN22 ${ }^{\mathrm{C} 1295}$ (orange) proteins were first preincubated for 10 min either in only buffer ( $\mathbf{- 1})$, with $300 \mu \mathrm{M}$ NADPH and $0.25 \mu \mathrm{M} \operatorname{TrxR} 1(\mathbf{\Delta})$, with $300 \mu \mathrm{M}$ NADPH, $0.25 \mu \mathrm{M}$ TrxR1 and $10 \mu \mathrm{M} \operatorname{Trx} 1(\boldsymbol{\nabla})$, or with $300 \mu \mathrm{M}$ NADPH, $0.25 \mu \mathrm{M} \operatorname{TrxR} 1$ and $10 \mu \mathrm{M} \operatorname{Trp} 14(\bullet)$, whereupon $\mathrm{H}_{2} \mathrm{O}_{2}(100 \mu \mathrm{M})$ and $1 \mathrm{mM} \mathrm{NaN}$ was added, except to the control $(\bullet)$, and samples were taken at indicated times for measurement of PTP activity. Data points represent mean \pm S.D. (error bars) $(n=3)$. 

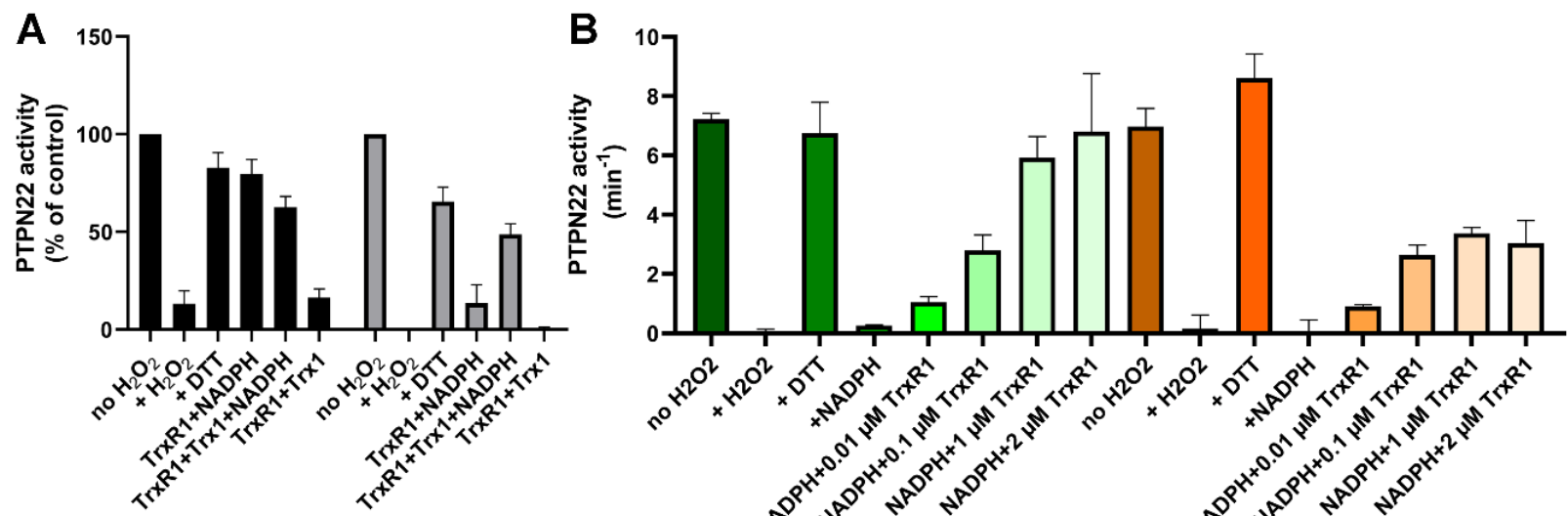

C
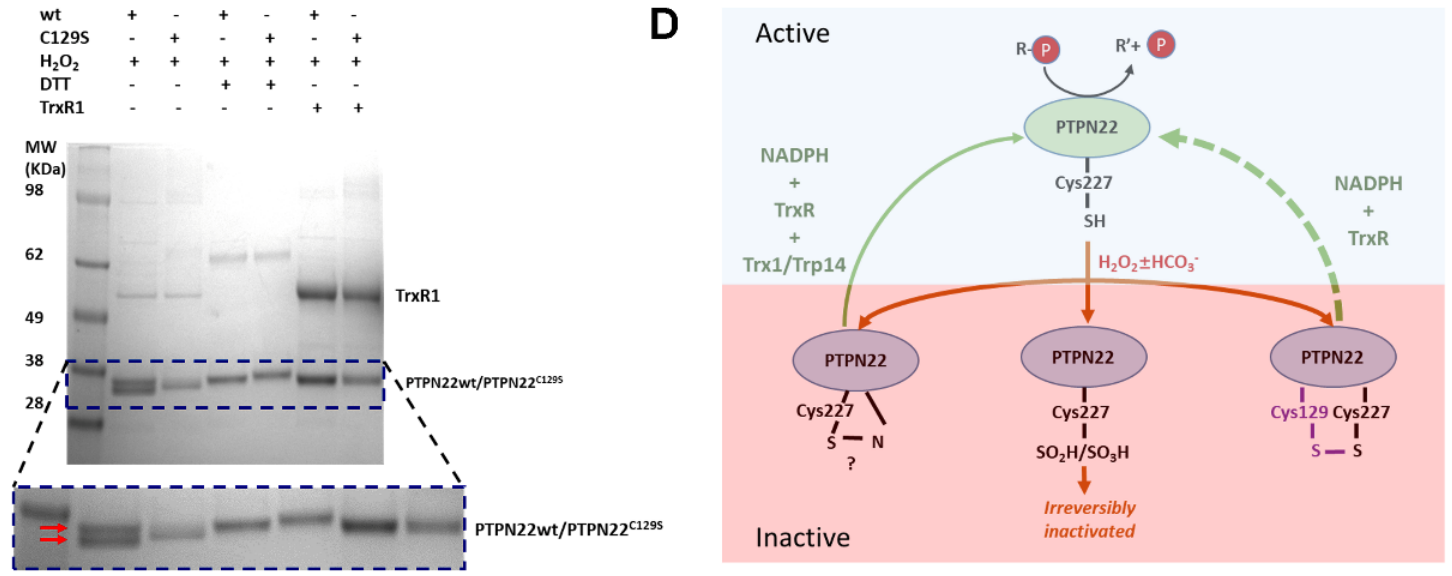

Fig.2. PTPN22 can be reactivated by TrxR1. A) Pre-reduced wild-type (black) or PTPN22 ${ }^{\mathrm{C} 1295}$ (grey) proteins were treated with $\mathrm{H}_{2} \mathrm{O}_{2}(1 \mathrm{mM})$ for 5 min whereupon residual $\mathrm{H}_{2} \mathrm{O}_{2}$ was removed by addition of catalase. Thereafter, the enzymes were incubated for $60 \mathrm{~min}$ at $37^{\circ} \mathrm{C}$ with either only buffer, DTT $(10 \mathrm{mM})$, or with combinations of TrxR1 $(2.5 \mu \mathrm{M})$ and NADPH $(300 \mu \mathrm{M})$ and Trx1 $(10 \mu \mathrm{M})$, as indicated. Finally, the samples were analyzed for PTP activity, with activity reported as percentage of control samples treated identically but without addition of $\mathrm{H}_{2} \mathrm{O}_{2}$. B) Pre-reduced PTPN22 (green) and PTPN22 ${ }^{\mathrm{C} 1295}$ (orange) were treated as described in A, reactivated with either $10 \mathrm{mM}$ DTT, or NADPH $(300 \mu \mathrm{M})$ and different concentrations of TrxR1 as indicated. After $60 \mathrm{~min}$ at $37^{\circ} \mathrm{C}$, samples were analyzed for PTP activity, given as turnover in $\mathrm{min}^{-1}$ ( $\mathrm{mol}$ of product/mol of enzyme/min). C) SDS-PAGE analysis of PTPN22 or PTPN22 ${ }^{\text {C1295 }}$ treated similarly to the assay shown in A) but incubated with $\mathrm{H}_{2} \mathrm{O}_{2}(100 \mu \mathrm{M})$, DTT $(10 \mathrm{mM})$ or TrxR1 $(0.5 \mu \mathrm{M}$ together with $300 \mu \mathrm{M}$ NADPH), as indicated in the figure. The samples were subsequently analyzed on a non-reducing SDS-PAGE. Note the presence of a double band only in oxidized PTPN22, but not in oxidized PTPN22 ${ }^{\mathrm{C} 129 \mathrm{~S}}$, that disappears upon incubation with either DTT or TrxR1 (double red arrows in the enlarged portion of the gel picture). D) A proposed model for redox regulation of PTPN22. Only the reduced form of the enzyme is active (top, light green), which upon oxidation with $\mathrm{H}_{2} \mathrm{O}_{2}$ and as further facilitated by bicarbonate $\left(\mathrm{HCO}_{3}{ }^{-}\right)$can form several oxidized species (bottom, purple), possibly being either a sulfenylamide as suggested for PTP1B or some other species that require the complete thioredoxin system for reactivation (left), as well as irreversibly oxidized with the catalytic C227 converted to sulfinic/sulfonic acid (middle), or by forming a disulfide with C129 (right). This disulfide was here found to be amenable to reduction directly by TrxR1, but as the PTPN22 ${ }^{\mathrm{C} 1295}$ mutant cannot form this species, it can also not be reactivated by that reduction path (dashed green arrow). Both PTPN22 and PTPN22 ${ }^{\mathrm{C} 129 \mathrm{~S}}$ can however be reactivated by the thioredoxin system from its other non-irreversibly oxidized states (solid green arrow). 
A

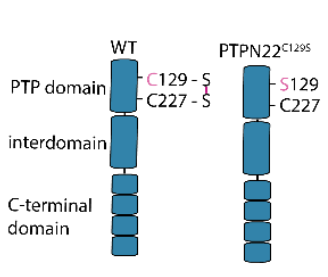

$\mathrm{E}$
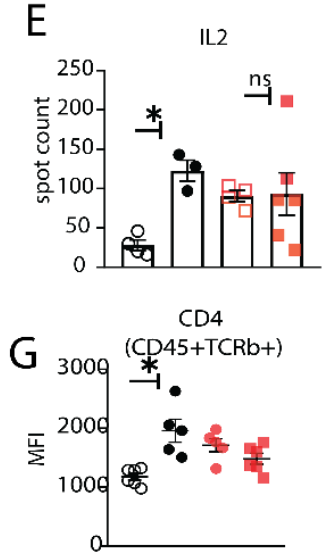

I

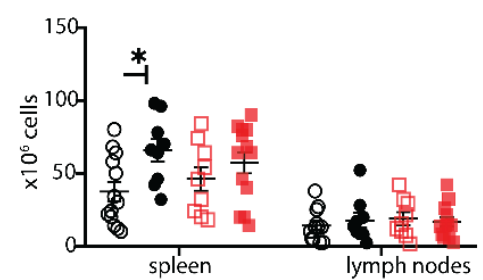

$\mathrm{K}$

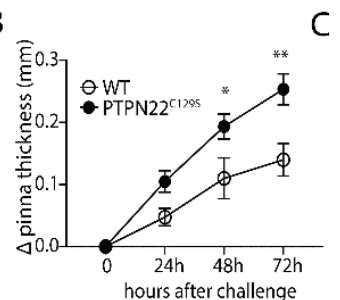

F
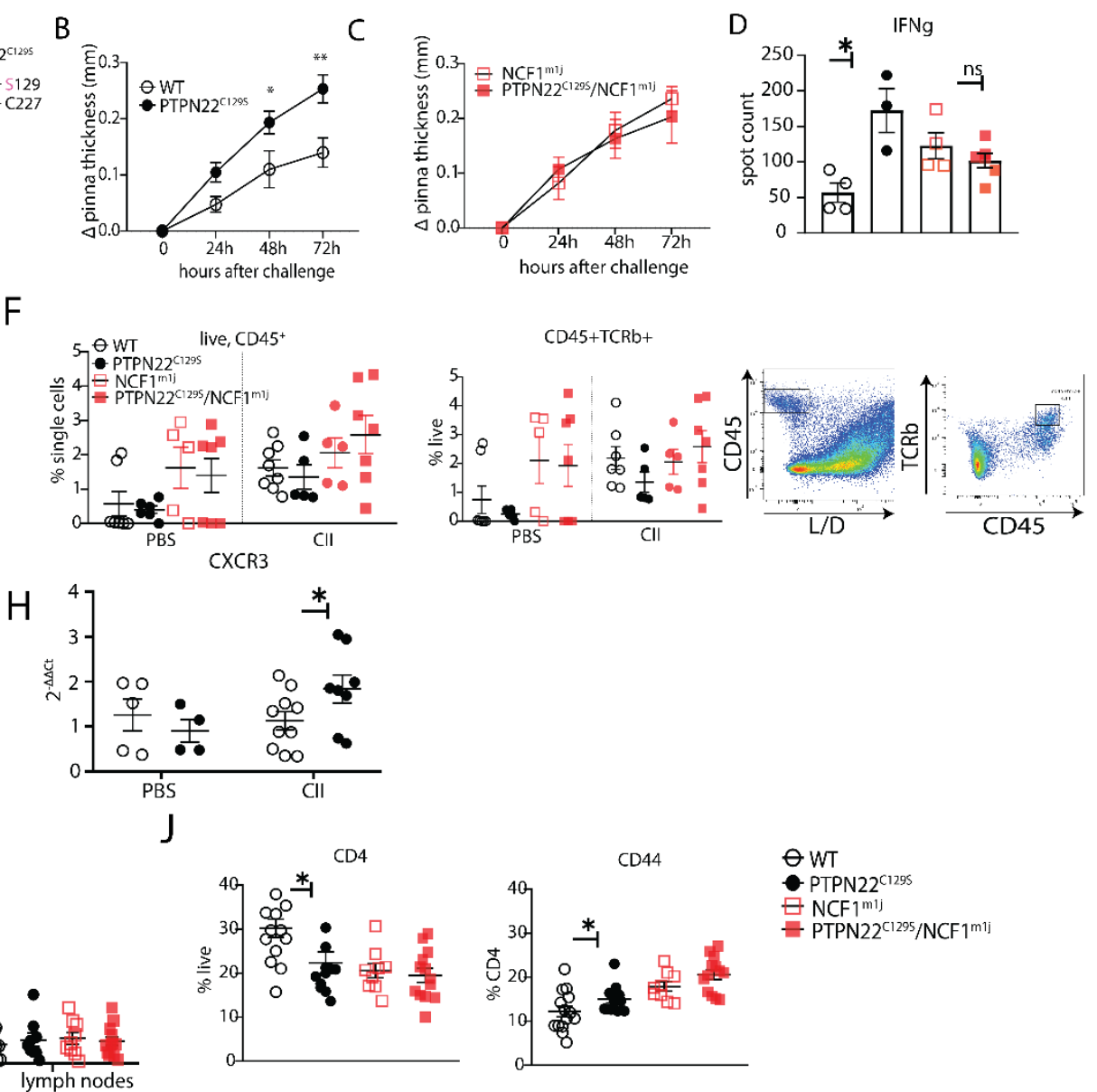

$\mathrm{CD} 3+\mathrm{CD} 4+$

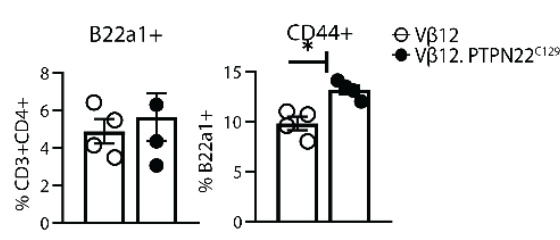

L
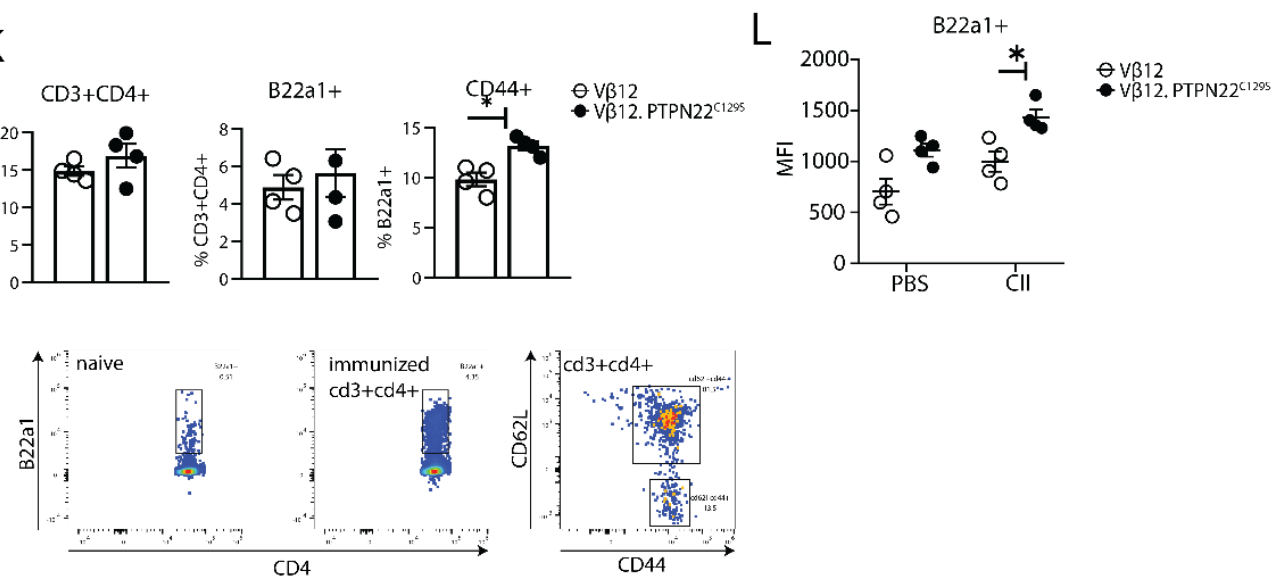

Fig.3: PTPN22 ${ }^{\text {c1295 }}$ enhances Th1-mediated inflammation via NOX2-mediated ROS. A) Schematic representation of wild-type and PTPN22 ${ }^{\mathrm{C} 1295}$ proteins; in the wild-type protein the catalytic cysteine 227 may form a disulfide bond with cysteine 129, whilst in the mutant, cysteine 129 is mutated into a serine, abrogating this disulfide bond. B-L) Mice were immunized according to DTH protocol with collagen type II and cell populations/ recall responses were analyzed 72 hours after challenge. B-C) Ear swelling of littermate wild-type $(n=8)$, PTPN22 $2^{\mathrm{C} 129 \mathrm{~S}}$ $(n=6), N_{C F}{ }^{m i 1 j}(n=5)$ and PTPN22 ${ }^{\mathrm{C} 1295} / \mathrm{NCF}^{\mathrm{m1j}}(n=7)$ mice at indicated time points after Cll challenge. Swelling shown as mean \pm SEM (2way ANOVA). Data is representative of four experiments. D-E) Measurement of antigenspecific interferon- $\gamma$ (IFN $\gamma$ )/ IL-2 T cell response against the immunodominant T cell epitope (rCII259-273) of collagen type 2 as measured by ELISpot in inguinal lymph nodes. F) Frequencies of indicated cell subsets in PBS- 
bioRxiv preprint doi: https://doi.org/10.1101/2021.12.02.470976; this version posted December 6, 2021. The copyright holder for this preprint (which was not certified by peer review) is the author/funder, who has granted bioRxiv a license to display the preprint in perpetuity. It is made available under aCC-BY 4.0 International license.

931 intensity (MFI) of CD4 within CII-injected ears measured by flow cytometry H) qPCR analysis of CXCR3 expression in PBS and CIl-injected ears I) Cell count in peripheral lymphoid organs at termination of DTH protocol J) Frequencies of indicated cell subsets within inguinal lymph nodes measured by flow cytometry K) Frequencies of indicated subsets in inguinal lymph nodes of V $312 / \mathrm{V} \beta 12 . P T P N 22^{\mathrm{C} 129 \mathrm{~S}}$ mice; flow cytometry plots show expansion of B22a1+ T cells upon immunization and representative gating for CD62L and CD44 L) MFI of B22a1 in PBS/CII-injected ears. Error bars represent mean \pm SEM. 
A

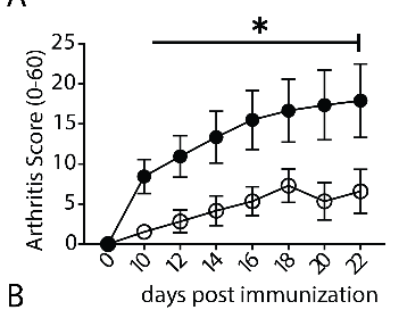

B

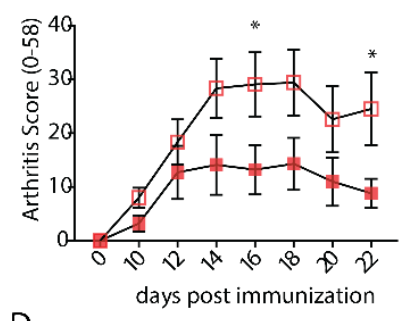

D
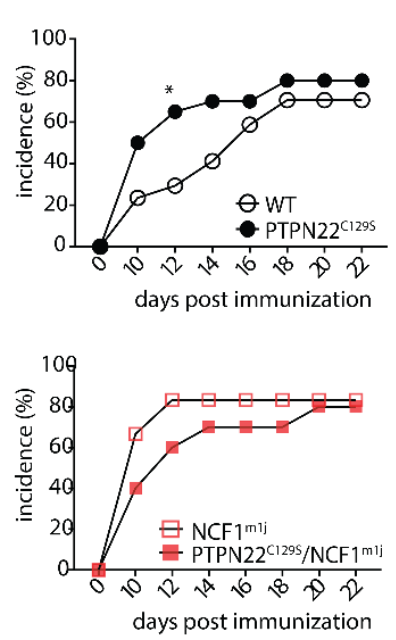

C

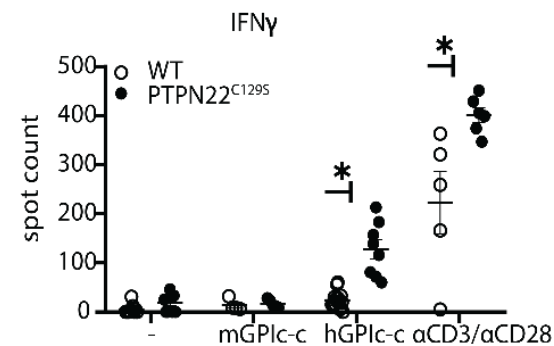

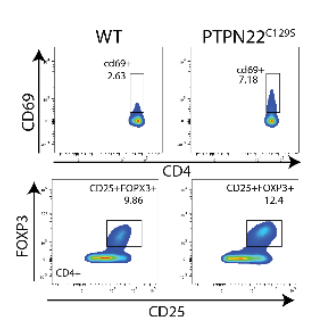

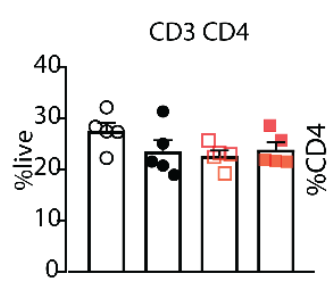

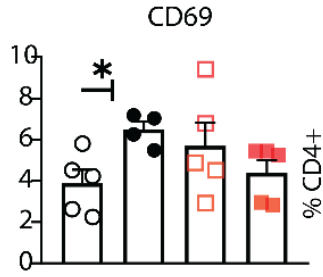
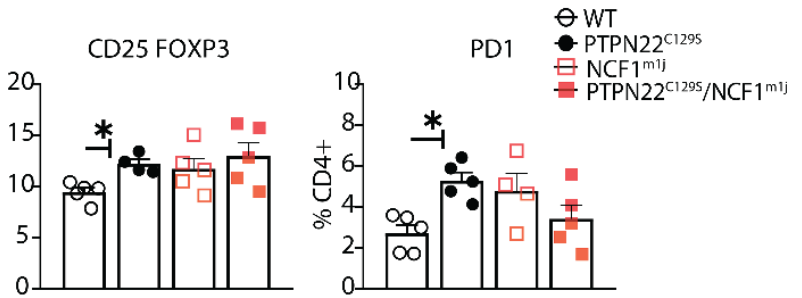

939

940

941

942

943

944

945

946

947

948
E

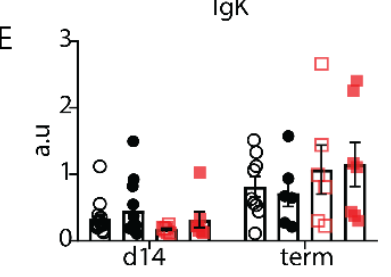

$\lg G 1$

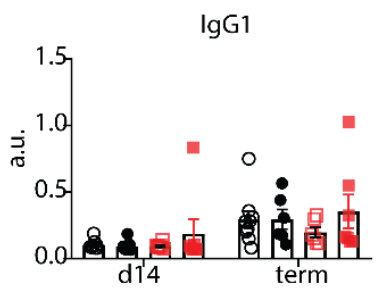

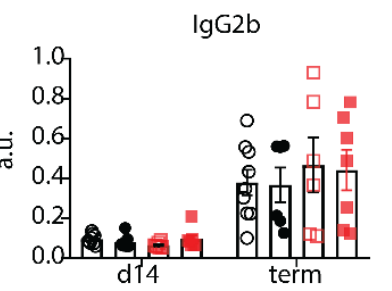

$\vartheta W T$

PTPN22 12

믈 $\mathrm{NCF} 1^{\mathrm{m} 1 \mathrm{j}}$

Fig.4: PTPN22 ${ }^{\mathrm{C} 1295}$ enhances arthritis development Arthritis was induced using human glucose-6-phosphate isomerase peptide (GPIp) and inflammation was monitored over 22 days. A-B) Clinical score (mean \pm SEM) and

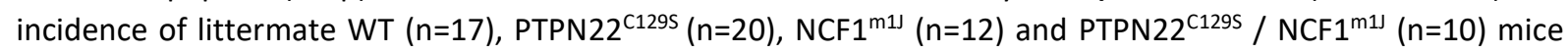
immunized with GPIp. Data from two pooled experiments (2way ANOVA). C) Antigen-specific interferon- $\gamma$ (IFNy) $T$ cell response against mouse/human GPIp as well as anti-CD3/anti-CD28 in lymph nodes by ELISpot D) Percentages of indicated cell subsets in lymph nodes at measured by flow cytometry; representative gating for CD69 and CD25+FOXP3+ cells shown. E) Levels of serum antibodies against hGPI day 14 post immunization and at arthritis endpoint measured by ELISA. Error bars represent mean \pm SEM. 
bioRxiv preprint doi: https://doi.org/10.1101/2021.12.02.470976; this version posted December 6, 2021. The copyright holder for this preprint (which was not certified by peer review) is the author/funder, who has granted bioRxiv a license to display the preprint in perpetuity. It is made available under aCC-BY 4.0 International license.
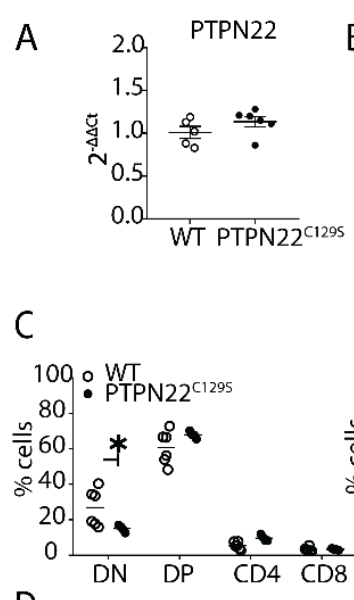

D
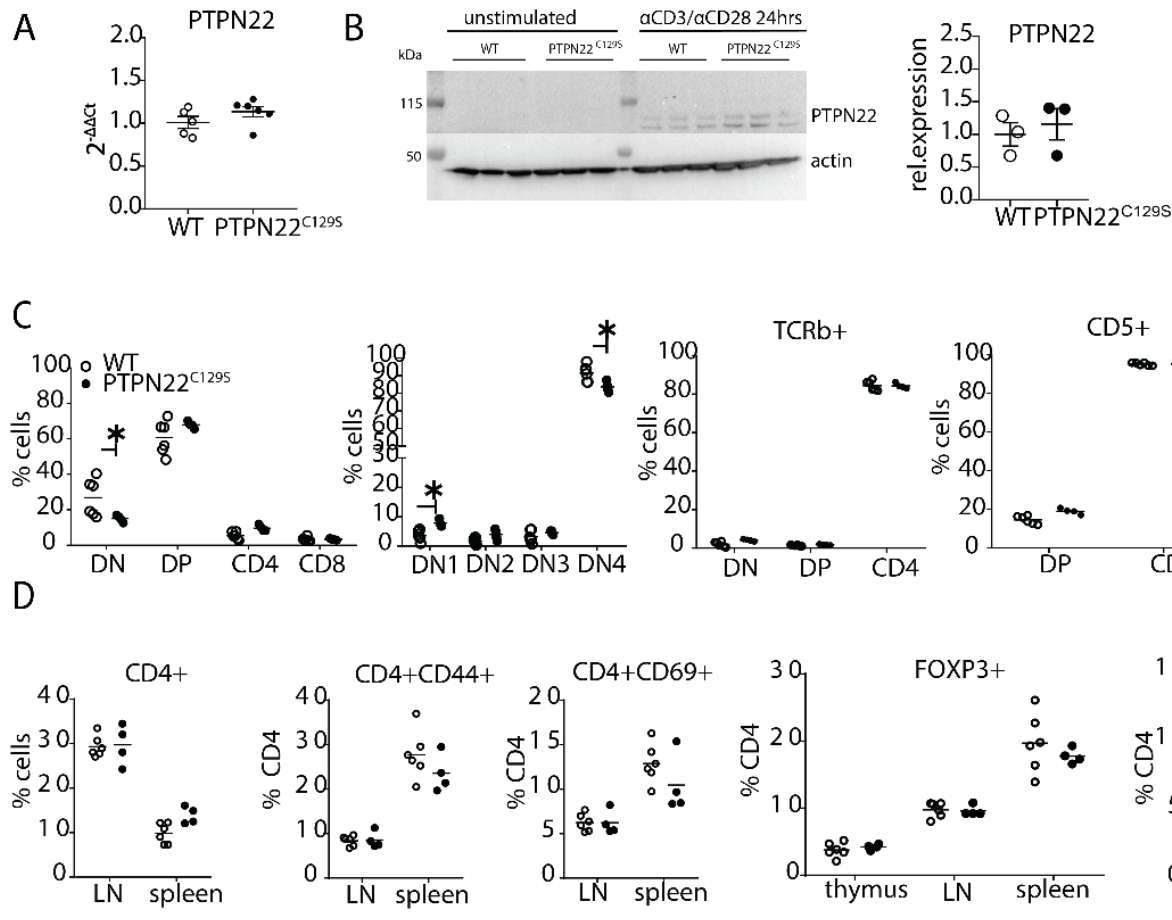

E
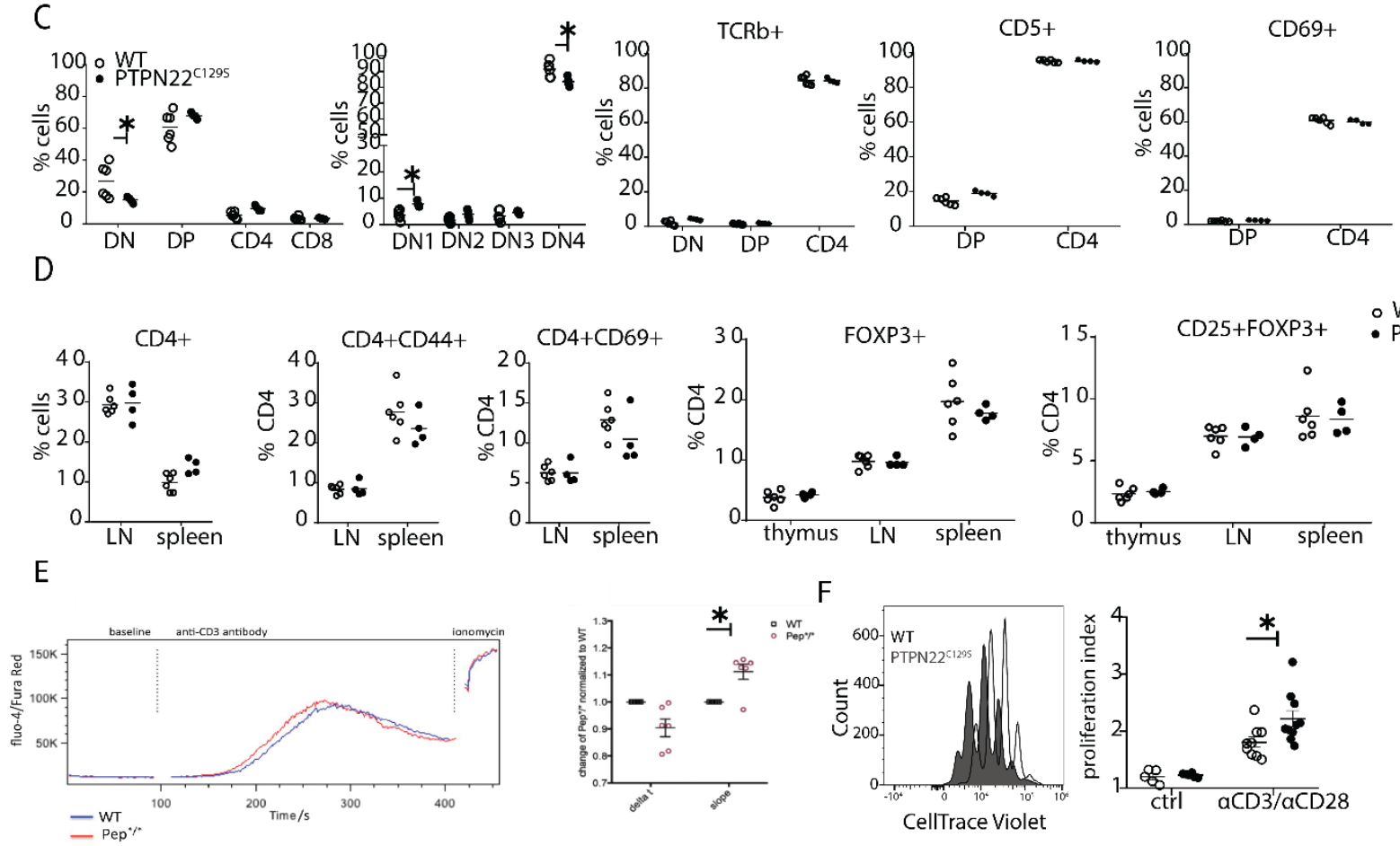

$\mathrm{G}$
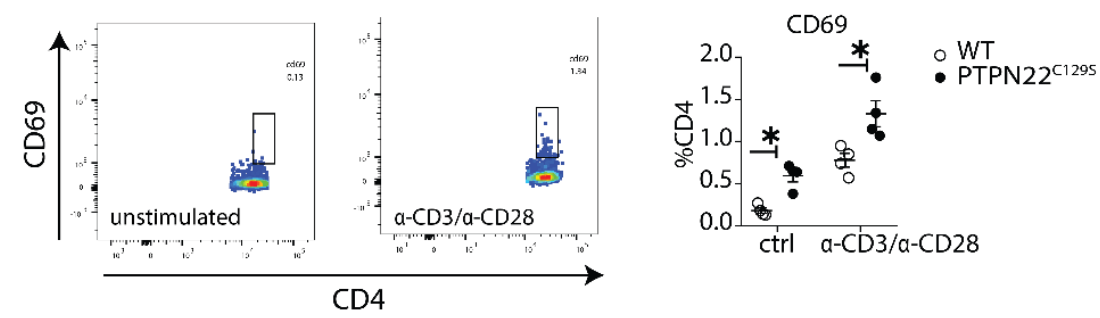

$\mathrm{H}$
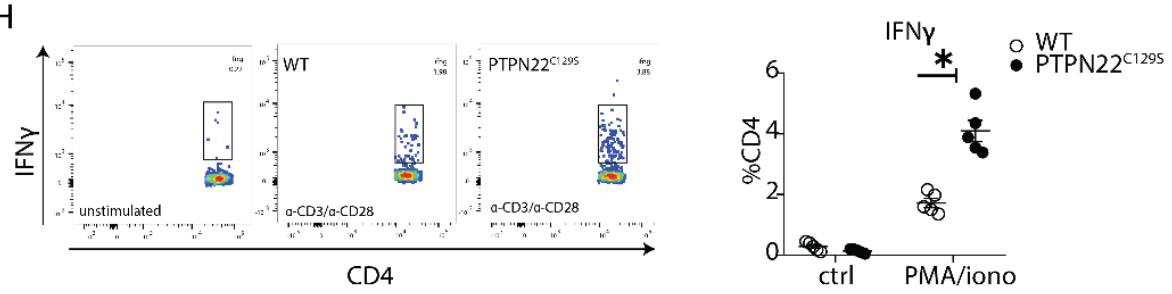
bioRxiv preprint doi: https://doi.org/10.1101/2021.12.02.470976; this version posted December 6, 2021. The copyright holder for this preprint (which was not certified by peer review) is the author/funder, who has granted bioRxiv a license to display the preprint in perpetuity. It is made available under aCC-BY 4.0 International license.

Fig.5: Enhanced activation and proliferation of PTPN22 ${ }^{\text {c1295 }} \mathbf{T}$ cells. A) Gene expression of PTPN22 in splenocytes shown as fold change over WT. B) Immunoblot analysis of PTPN22 expression in sorted CD4 T cells either unstimulated or activated in vitro with $1 \mathrm{ug} / \mathrm{ml}$ anti-CD3/CD28 for 24 hours. Each lane shows cells from a distinct mouse and relative expression to the right was calculated as by normalizing to loading control (actin) C-D) Analysis of T cell populations in naïve mice via flow cytometry. C) Analysis of double negative (DN), double positive (DP) and single positive CD4 and CD8 thymic populations in 10-week old littermate mice as well as expression of TCRb, CD5 and CD69 on various subsets D) Frequencies of activated (CD44+/ CD69+) and regulatory (FOXP3+) CD4+ T cells in thymus and secondary lymphoid organs. E) Intracellular calcium measurement in CD4 T cells at baseline, after stimulation with anti-CD3, and ionomycin to achieve maximum $\mathrm{Ca}^{2+}$ influx via staining with Fluo4 and FuraRed. Shown is a representative image of the change in ratio of fluo4 to FuraRed expression over time (blue=wild-type; red= PTPN22 ${ }^{\mathrm{C} 1295}$ ). Quantification to the right shows slope value which describes how fast the peak of $\mathrm{Ca}^{2+}$ influx is reached [77] F) Proliferation of CD4+ T cells as assessed by CellTrace Violet dilution after 96-hour in vitro stimulation with $1 \mathrm{ug} / \mathrm{ml}$ anti-CD3/CD28. Proliferation Index is the total number of divisions divided by the number of cells that went into division. Representative proliferation peaks on the left (clear=wildtype, black= PTPN22 ${ }^{\mathrm{C} 129 \mathrm{~S}}$ ) and quantification on the right (ctrl refers to unstimulated samples). G-H) Ex vivo stimulated CD4 T cells were assessed for CD69 expression/ IFN $\gamma$ production after stimulation with anti-CD3/antiCD28 or PMA/ionomycin, respectively. Representative gating shown. Error bars represent mean \pm SEM. 
bioRxiv preprint doi: https://doi.org/10.1101/2021.12 02 470976; this version posted December 6, 2021. The copyright holder for this preprint (which was not certified by peer review) is the author/funder, who has granted bioRxiv a license to display the preprint in perpetuity. It is made available under aCC-BY 4.0 International license.

A

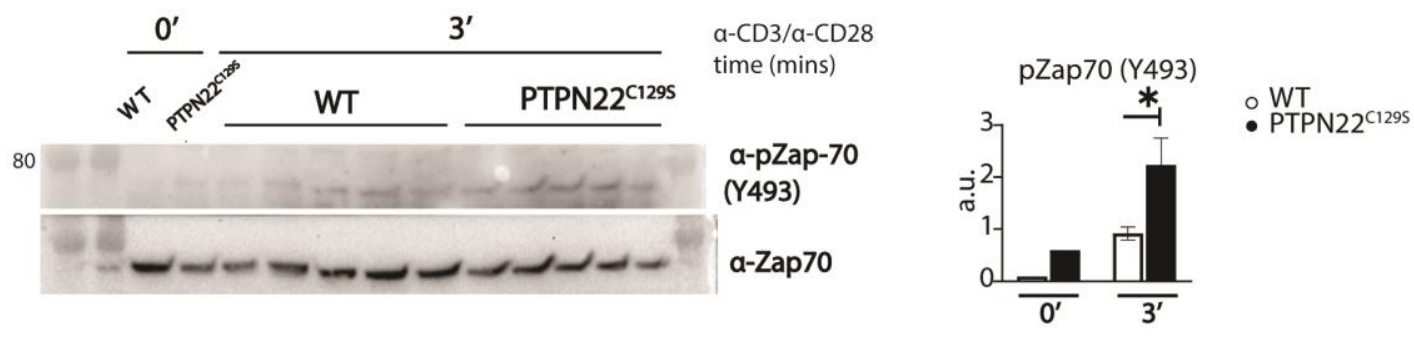

B
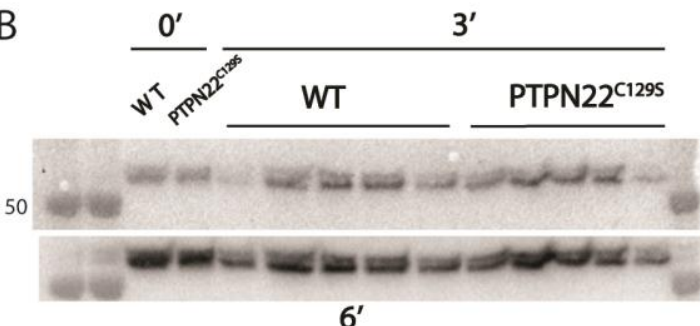

a-CD3/a-CD28

time (mins)

a-pSrc

(Y416)

pSrc (Y416)

a-Fyn/a-LCK

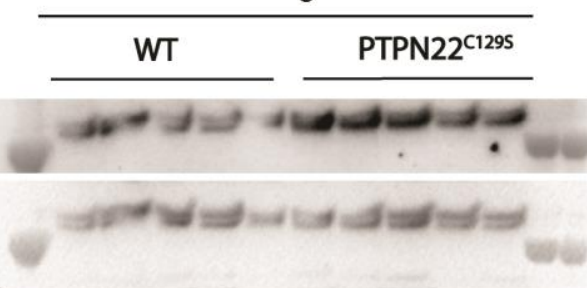

a-pSrc

(Y416)

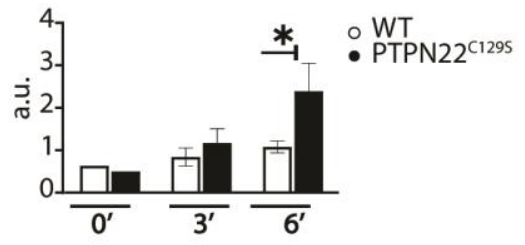

C

a-Fyn/a-LCK

WT

PTPN22 ${ }^{\mathrm{C} 1295}$

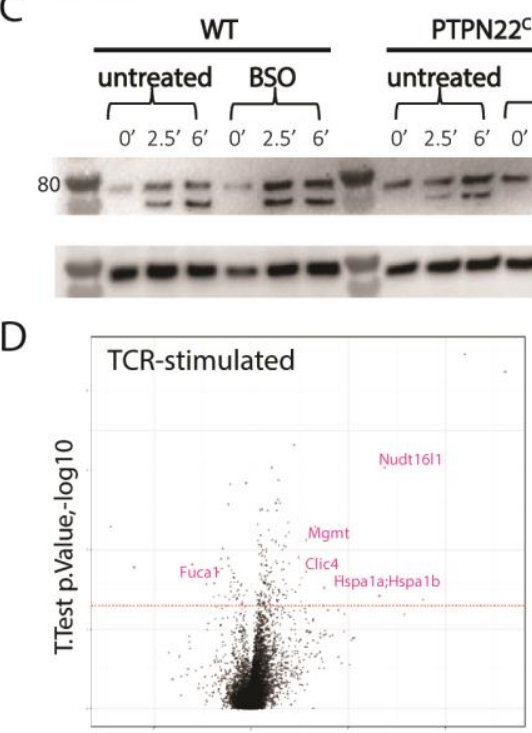

Fold Change, log2
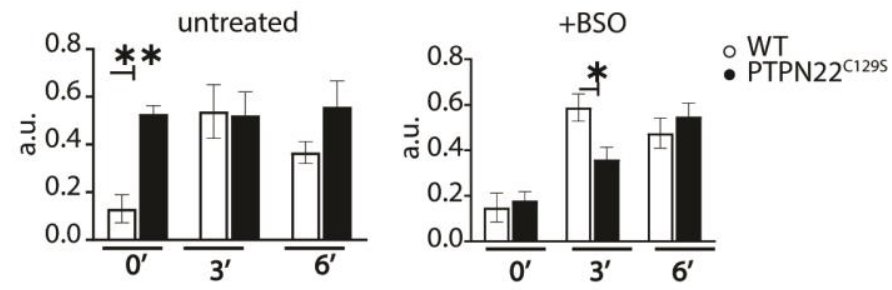

a-PKC

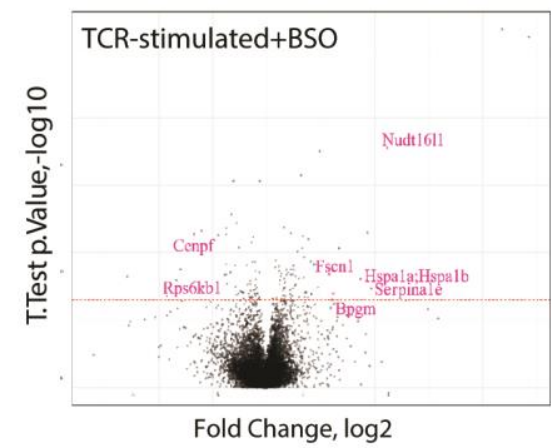

E

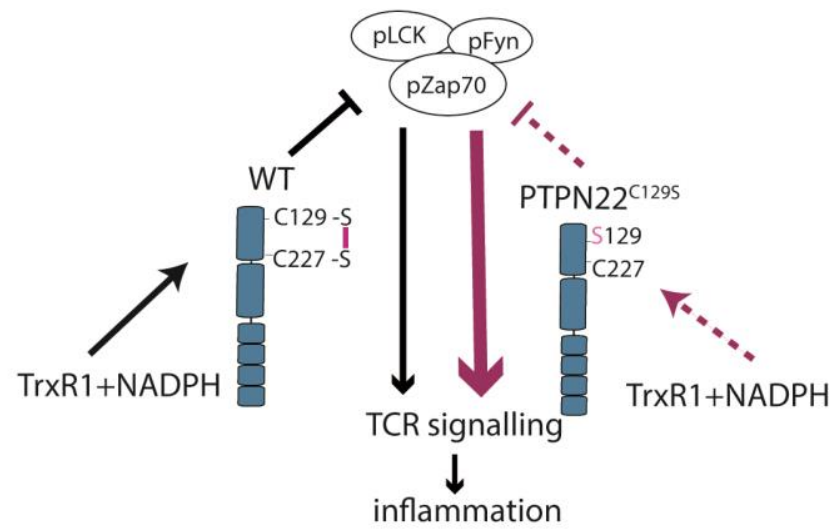

inflammation 
bioRxiv preprint doi: https://doi.org/10.1101/2021.12.02.470976; this version posted December 6, 2021. The copyright holder for this preprint (which was not certified by peer review) is the author/funder, who has granted bioRxiv a license to display the preprint in perpetuity. It is made available under aCC-BY 4.0 International license.

Fig.6: Enhanced phosphorylation of PTPN22 ${ }^{\mathrm{C129S}}$ targets and increased PKC $\theta$ expression. A-B) Lymph node cells were stimulated for indicated time points with anti-CD3 plus anti-CD28 and phosphorylation was detected via immunoblotting of total cell lysates with antibodies against activated Zap-70 (A) and Src kinases (B). Antibody against p-Src (Y416) binds to Lck Y394 and Fyn Y417 with the top band representing pFyn and the bottom band pLCK, see [78]. Each lane reflects distinct wild-type/ PTPN22 ${ }^{\mathrm{C} 129 \mathrm{~S}}$ mice and unlabeled lanes show molecular weight markers. Quantification to the right was calculated as phosphorylation signal/ total signal normalized to loading control. C) Lymph node cells were cultured 24hours with/ without BSO, a glutathione depletion agent, before in vitro activation with anti-CD3 plus anti-CD28 for indicated time points. Total lysate was analyzed for PKC $\theta$ expression via immunoblotting. Representative image shown. Quantification to the right was calculated as phosphorylation signal/ total signal normalized to loading control (WT=6, PTPN22 ${ }^{\mathrm{C} 129 \mathrm{~S}}=8$ ). D) Volcano plots comparing the proteomic profile of sorted CD4+ T cells from wild-type and PTPN22 ${ }^{\mathrm{C} 1295}$ mice which were stimulated with anti-CD3 plus anti-CD28 for 5 hours either with or without prior treatment (24h) with BSO. Four mice per group were used for proteomic analysis and p-values were calculated by Welch's t-test. Proteins that were significantly up/downregulated in PTPN22 ${ }^{\mathrm{C} 129 \mathrm{~S}}$ mutants are highlighted in red. E) A proposed model for redox regulation of PTPN22 in vivo: upon oxidative pressure within the cell C227 of PTPN22 forms a disulfide bond with the back-door cysteine $\mathrm{C} 129$ as a means of protection from irreversible oxidation and inactivation. When the C227-C129 bond cannot be formed, as is the case in PTPN22 ${ }^{\mathrm{C} 1295}$ mutant, PTPN22 is less sensitive to reactivation by the thioredoxin system which leads to increased TCR signaling and inflammation. Error bars represent mean \pm SEM. 
bioRxiv preprint doi: https://doi.org/10.1101/2021.12.02.470976; this version posted December 6, 2021. The copyright holder for this preprint (which was not certified by peer review) is the author/funder, who has granted bioRxiv a license to display the preprint in perpetuity. It is made available under aCC-BY 4.0 International license.

\section{Supplementary Figures}

\begin{tabular}{|c|c|}
\hline$\# 1$ & PTPN22 \\
\hline \#2 & PTPN22 + 10 $\mu \mathrm{MH} 2 \mathrm{O} 2$ \\
\hline$\# 3$ & 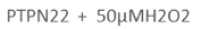 \\
\hline$\# 4$ & PTPN22 + 500 $\mu$ MH2O2 \\
\hline
\end{tabular}

\begin{tabular}{|l|l|}
\hline & concentration \\
\hline PTPN22 & $1400 \mathrm{nM}$ \\
\hline H2O2 & $10,50,500 \mu \mathrm{M}$ \\
\hline DT & $10 \mathrm{mM}$ \\
\hline
\end{tabular}

\begin{tabular}{|c|c|}
\hline$\# 1$ & PTPN22 \\
\hline \#2 & 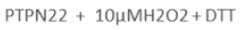 \\
\hline \#3 & 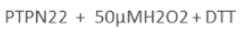 \\
\hline \#4 & PTPN $22+500 \mu \mathrm{MH} 2 \mathrm{O} 2+\mathrm{DTT}$ \\
\hline
\end{tabular}
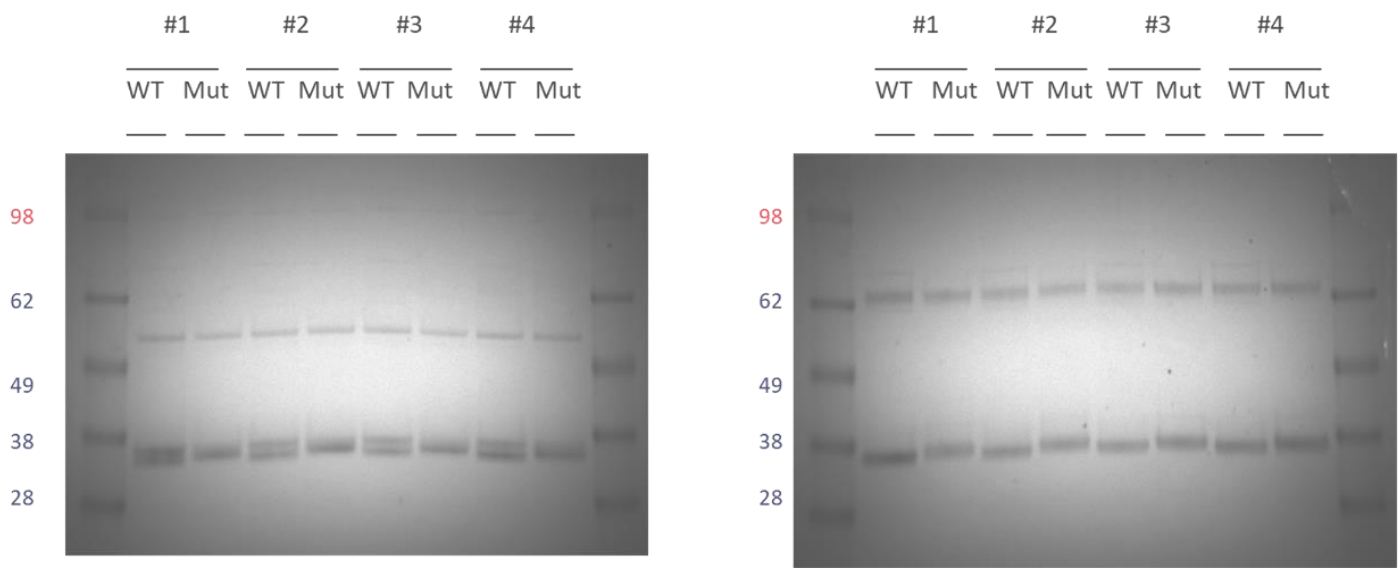

Fig. S1. Reproducibility and $\mathrm{H}_{2} \mathrm{O}_{2}$-concentration dependence of the double band appearing in oxidized PTPN22 but not in PTPN22 ${ }^{\text {c1295 }}$, always fully reducible using subsequent treatment with DTT. 
A

C

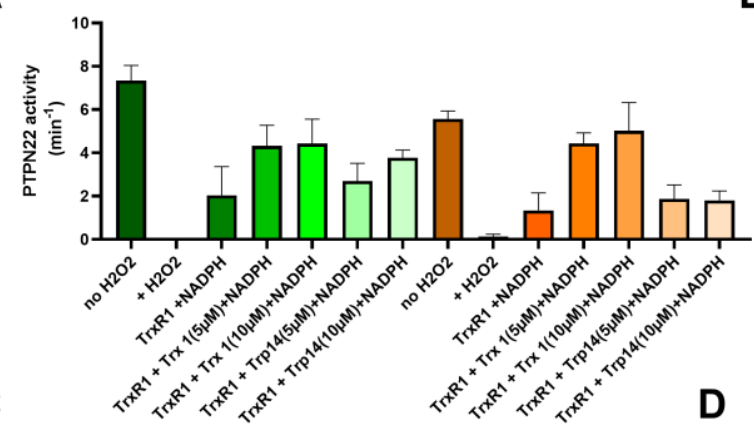

B

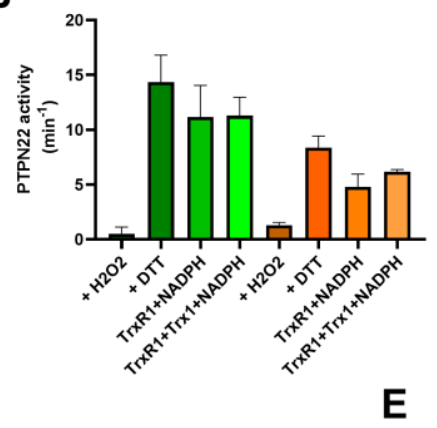

1000

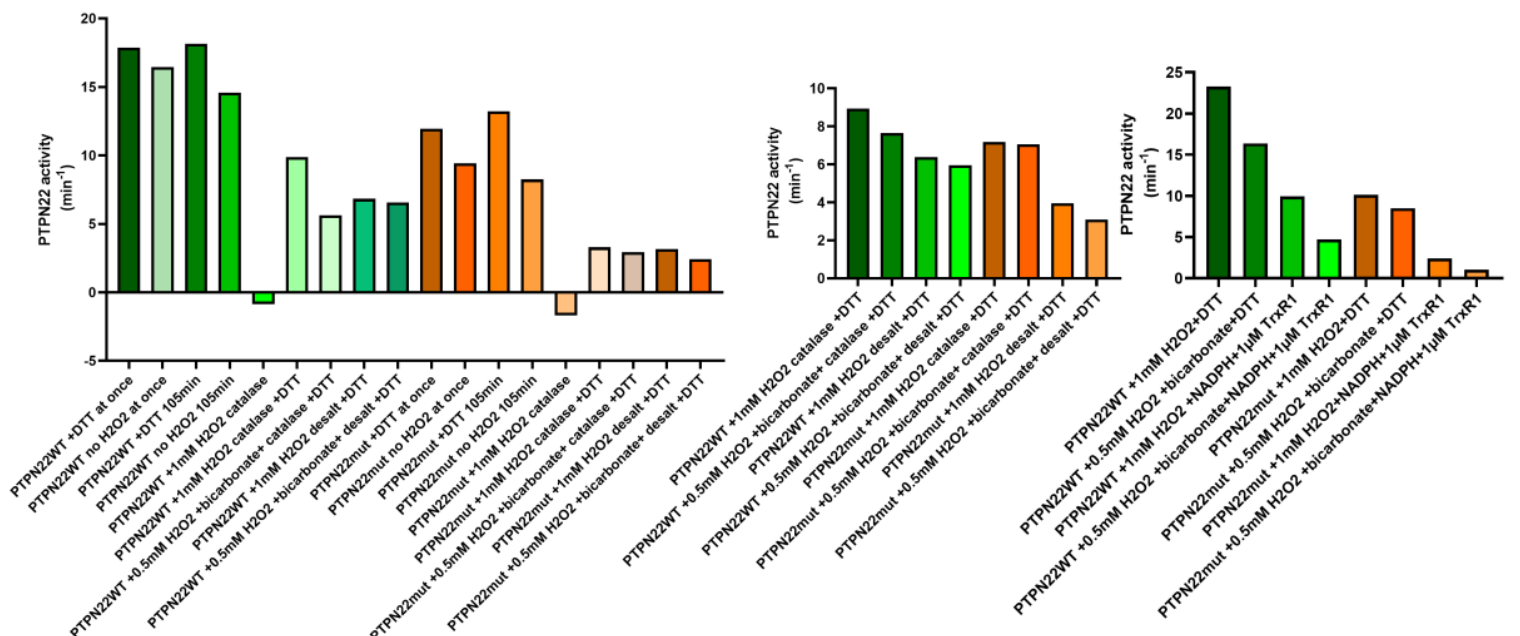

Fig.S2. C129S mutant PTPN22 is less sensitive to TrxR1 reactivation as compared to WT PTPN22.

A) Reduced wildtype (green) and C129S mutant (orange) PTPN22 (1400 nM) was pre-oxidized by $\mathrm{H}_{2} \mathrm{O}_{2}$ and then reactivated with TrxR1 $(0.05 \mu \mathrm{M})(18 \mathrm{units} / \mathrm{mg})$ and NADPH $(300 \mu \mathrm{M})$ with or without TRP14 (5 or $10 \mu \mathrm{M})$ or Trx1 (5 or $10 \mu \mathrm{M}$ ), as indicated. After incubation for $60 \mathrm{~min}$ at $37^{\circ} \mathrm{C}$, samples were analyzed for PTP activity. B) Reduced wildtype (green) and C129S mutant (orange) PTPN22 (1400nM) was treated with $\mathrm{H}_{2} \mathrm{O}_{2}(100 \mu \mathrm{M})$ for 30 min and then desalted to remove residual $\mathrm{H}_{2} \mathrm{O}_{2}$ with subsequent reactivation with DTT $(10 \mathrm{mM})$ or TrxR1 (2.5 $\left.\mu \mathrm{M}\right)$ (18 units/mg) with or without NADPH $(300 \mu \mathrm{M})$ and Trx1 $(10 \mu \mathrm{M})$. After $60 \mathrm{~min}$ at $37^{\circ} \mathrm{C}$, samples were analyzed for PTP activity. C) Reduced wildtype (green) and C129S mutant (orange) PTPN22 (1400nM) was oxidized using $\mathrm{H}_{2} \mathrm{O}_{2}$ with or without addition of $25 \mathrm{mM}$ bicarbonate as described in the main text, but some groups included catalase and some reactivated with $10 \mathrm{mM}$ DTT, as indicated. After $60 \mathrm{~min}$ at $37^{\circ} \mathrm{C}$, samples were analyzed for PTP activity. D-E) Reduced wildtype (green) and C129S mutant (orange) PTPN22 (1400 nM) was treated as described in $C$ and reactivated with either DTT $(10 \mathrm{mM})$ or TrxR1 $(1 \mu \mathrm{M})(18$ units/mg) and NADPH $(300 \mu \mathrm{M})$, as indicated. After $60 \mathrm{~min}$ at $37^{\circ} \mathrm{C}$, samples were analyzed for PTP activity. 

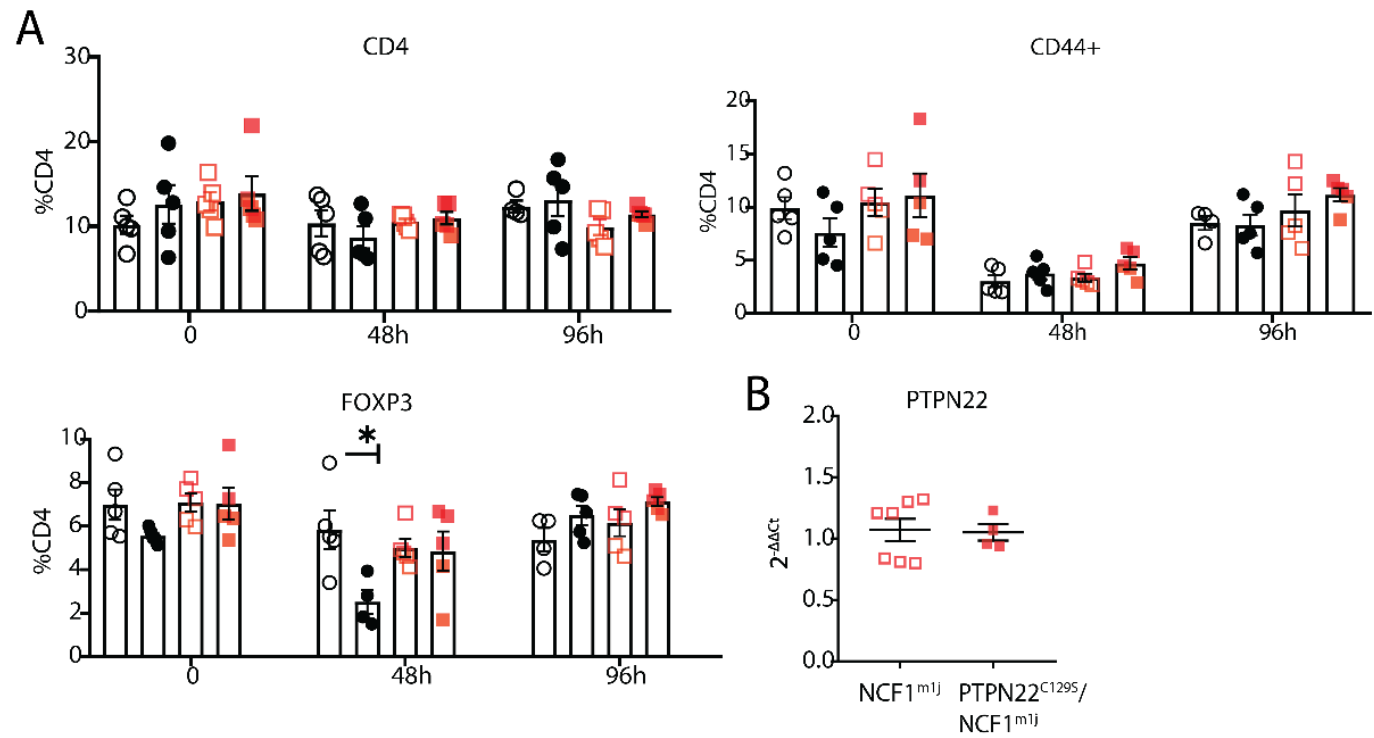

\section{C}

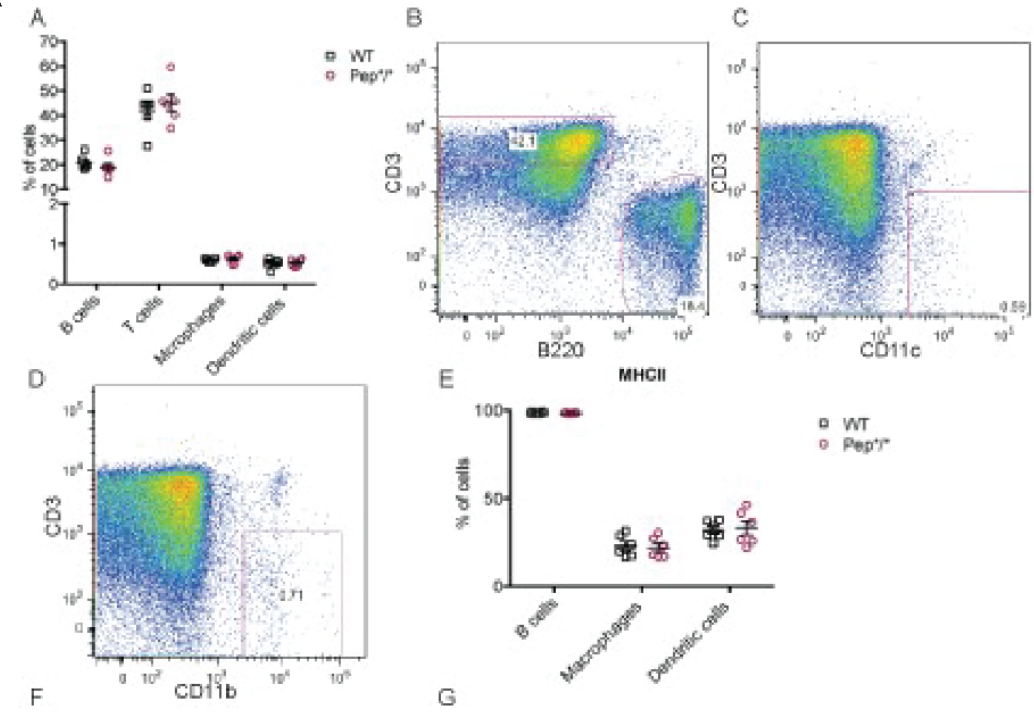

D
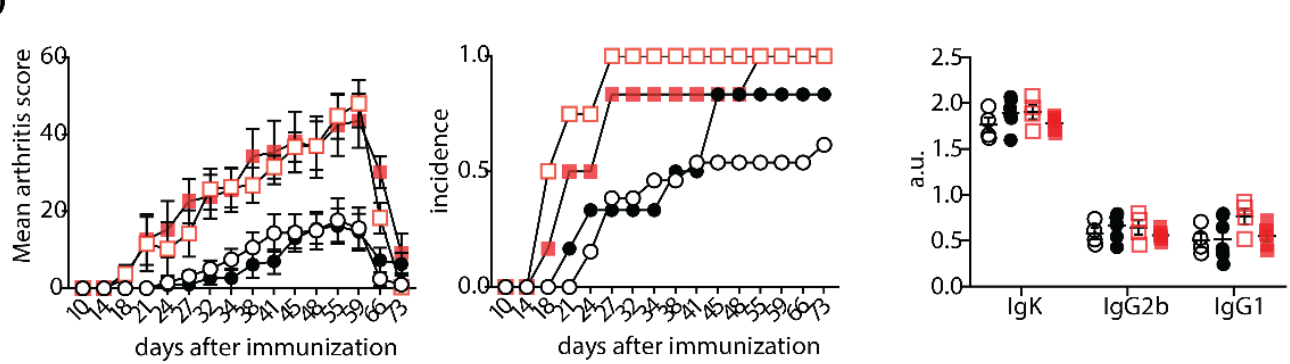

Fig.S3: A) Flow cytometry measurement of indicated cell subsets in blood in mice 0, 48 and 96 hours after primary immunization with CII. B) Gene expression of PTPN22 in splenocytes from NCF1 ${ }^{\mathrm{m} 1 \mathrm{~s}}$ and PTPN22 ${ }^{\mathrm{C} 129 \mathrm{~s}} /$ NCF1 $^{\mathrm{m} 1 \mathrm{~J}}$ mice shown as fold change over NCF1 ${ }^{\mathrm{m1j}}$. C) Percentage of B cells (B220+), T cells $(\mathrm{CD} 3+)$, macrophages $(\mathrm{CD} 11 \mathrm{~B}+)$, dendritic cells $(\mathrm{CD} 11 \mathrm{~B}+)$ in peripheral lymphoid organs as well as MHC II expression on $B$ cells, macrophages and dendritic cells. D) Clinical score (mean $\pm S E M)$, incidence and serum antibody levels at termination of collagen induced arthritis in littermate mice. 
bioRxiv preprint doi: https:/doi org/10.1101/2021.12.02 470976; this version posted December $6,2021$. The copyright holder for this preprint (which was not certified by peer review) is the author/funder, who has granted bioRxiv a license to display the preprint in perpetuity. It is made available under aCC-BY 4.0 International license.

Supplemental Table 1: Primer list

\begin{tabular}{|l|l|l|}
\hline & Forward (5'-->3') & Reverse (3'-->5') \\
\hline PTPN22 & ACAAGGGGCTGAAGCGGAGAGC & AAAGCGCCGGGGCTGTG \\
\hline Actin & AACCATGAAAAGATGACCCAGAT & GTCCATCACAATGCCTGTGGTA \\
\hline CXCR3 & TACCTTGAGGTTAGTGAACGTCA & CGCTCTCGTTTTCCCCATAATC \\
\hline
\end{tabular}

\section{Supplemental Table 2: antibody list}

\begin{tabular}{|c|c|c|c|}
\hline Marker & Fluorophore & Manufacturer & Cat.No. \\
\hline CD45 & APC & Biolegend & 103111 \\
\hline CD4 & Qdot605 & $B D$ & 563151 \\
\hline CD4 & Pacific Blue & $B D$ & 558107 \\
\hline $\mathrm{TCRb}$ & PercpCy5.5 & $B D$ & 560657 \\
\hline TCRgd & PE-Сy7 & Biolegend & 118123 \\
\hline CD44 & AF700 & Biolegend & 103026 \\
\hline CD44 & FITC & $B D$ & 561859 \\
\hline CD44 & PercpCy5.5 & $B D$ & 560570 \\
\hline CD25 & PE & $B D$ & 553075 \\
\hline CD25 & FITC & Biolegend & 102017 \\
\hline CD62L & PE-Cy7 & Biolegend & 104417 \\
\hline FOXP3 & APC & Invitrogen & $17-5773-82$ \\
\hline FOXP3 & $\mathrm{PE}$ & Invitrogen & $12-5773-82$ \\
\hline CD69 & $\mathrm{PE}$ & Biolegend & 104507 \\
\hline CD103 & $\mathrm{PE}$ & $\mathrm{BD}$ & 557495 \\
\hline $\mathrm{IFN \gamma}$ & APC & $B D$ & 505807 \\
\hline $\begin{array}{l}\text { B22a- } \\
\text { biotin }\end{array}$ & $\begin{array}{c}\text { Streptavidin-BV421 } \\
\text { (Biolegend } \\
405226)\end{array}$ & In-house & \\
\hline
\end{tabular}

